\title{
RESPONDING TO THE SETTLEMENT NEEDS OF NEWCOMERS TO CANADA: THE ROLE OF COMMUNITY ORGANIZATIONS IN THE GREATER TORONTO AREA
}

\author{
by
}

Erica Wright
Bachelor of Commerce, Ryerson University, 2017

A Major Research Paper

presented to Ryerson University

in partial fulfillment of the

requirements for the degree of

Master of Arts

in the program of

Immigration and Settlement Studies

Toronto, Ontario, Canada, 2018

(C) Erica Wright, 2018 


\section{AUTHOR'S DECLARATION FOR ELECTRONIC SUBMISSION OF A MAJOR RESEARCH PAPER}

I hereby declare that I am the sole author of this Major Research Paper (MRP). This is a true copy of the MRP, including any required final revisions.

I authorize Ryerson University to lend this MRP to other institutions or individuals for the purpose of scholarly research.

I further authorize Ryerson University to reproduce this MRP by photocopying or by other means, in total or in part, at the request of other institutions or individuals for the purpose of scholarly research.

I understand that my MRP may be made electronically available to the public.

\section{Erica Wright}




\title{
RESPONDING TO THE SETTLEMENT NEEDS OF NEWCOMERS TO CANADA: THE ROLE OF COMMUNITY ORGANIZATIONS IN THE GREATER TORONTO AREA
}

\author{
Erica Wright \\ Master of Arts 2018 \\ Immigration and Settlement Studies \\ Ryerson University
}

\begin{abstract}
This study analyzes the role of grassroots organizations in the Greater Toronto Area who support newcomers to Canada. A qualitative thematic analysis was used, with staff from three grassroots organizations and two key informants participating. The study aims, first, to gather practical knowledge from these organizations about the actions needed to improve settlement outcomes for newcomers. Secondly, it seeks to learn what challenges grassroots organizations face in continuing and expanding their services, and how they can be supported in their work. The organizations of focus do not provide direct, government-funded settlement services, but work towards goals of long-term immigrant success and integration. Findings included the need for more responsive and culturally-relevant programming among settlement organizations, the challenges with attaining funding, and the importance of partnerships among related institutions. These actors have valuable insights on newcomers' current settlement needs and can make important knowledge contributions to the settlement sector.
\end{abstract}

Key words: immigrants; settlement and integration; public services; grassroots organizations; Canada 


\section{Acknowledgements}

I would like to express my sincere gratitude to my supervisor, Dr. Henry Parada, for his support and for sharing his knowledge throughout the process of writing this MRP. I would also like to thank my second reader, Dr. John Shields, for his interest and advice on this project, and whose research has greatly influenced my work.

A wholehearted thank you to those who participated in this study, for their time and for their

confidence in this work. Without their knowledge, experience and dedication this research would not have been possible. 


\section{Dedication}

To my mother, for your infinite love and for always believing in me,

To Anthony, for inspiring me, for taking such good care of me,

$\&$ to the leaders, changemakers, and social justice warriors who devote their lives in service to their communities. You are making a world of difference. 


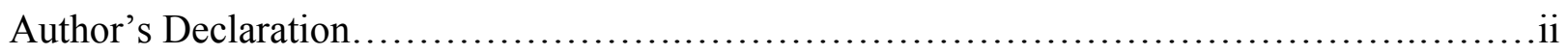

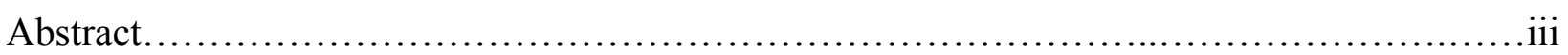

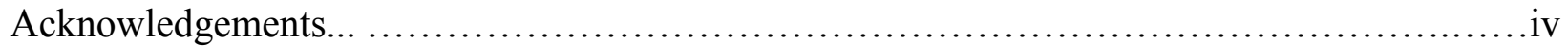

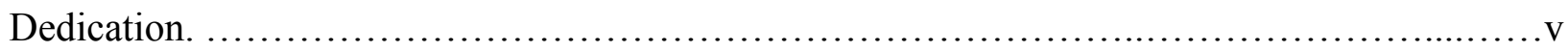

Chapter 1. Introduction.........................................................

Chapter 2. Literature Review....................................................... 5

2.1. Overview of the Formal Settlement Sector in Canada............................5

2.2. Current Issues in Newcomer Settlement and Integration.........................17

Chapter 3. Theoretical Perspective...............................................25

Chapter 4. Methodology ...................................................... 30

4.1. Research Design...................................................30

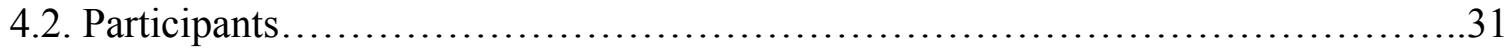

4.3. Data Collection and Analysis.......................................... 33

4.4. Concepts........................................................

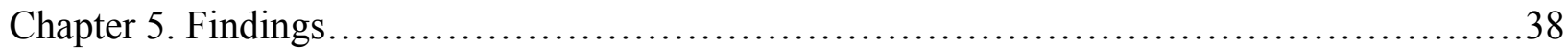

5.1. Responses to the Needs of Newcomer Communities........................... 38

5.2. The Need for Culturally and Contextually Relevant Programming..................48

5.3. Building Partnerships and Investing in People...............................53

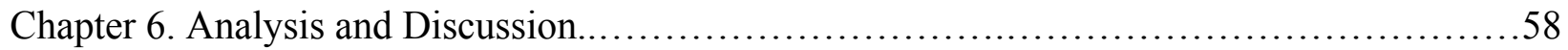

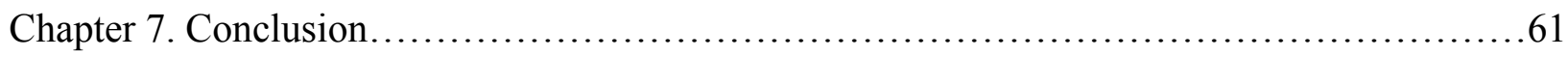

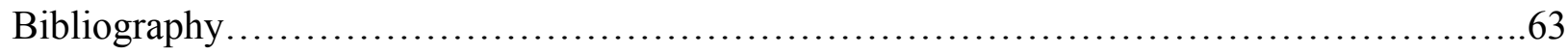




\section{Chapter 1. Introduction}

Since the 1970s Canada has been one of the main immigrant-receiving countries and has been recognized internationally for having a strong model for immigrant settlement and integration (Shields, Drolet \& Valenzuela, 2016). In 2016, Canada welcomed more than 296,000 permanent residents and had set a target of 300,000 for 2017, with projected increases up to 360,000 in 2020 (Government of Canada, 2017a). Canada's immigration policy emphasizes the important role immigrants play in meeting the needs of an expanding labour market and growing economy. The highest category of admissions continues to be economic class immigrants which included about 156,000 permanent residents in 2016. Additionally, in 2016 more than 62,000 people were admitted to Canada as resettled refugees and 78,000 in the Family Class (Government of Canada, 2017a). These numbers, up from a maximum target of 265,000 immigrants in 2014 (Government of Canada, 2013), are in part a reflection of a government which sees immigration as necessary for the economic and demographic viability of Canada. Temporary work migration and international students are also an enormous contribution to the Canadian economy. Those who came to Canada temporarily in 2016 contributed $\$ 32.2$ billion to the economy, and Canada issued over 286,000 work permits to temporary workers (Government of Canada, 2017a).

With a growing and dynamic immigrant population, it is crucial that Canada is able to provide support to newcomers settling into cities. In particular, literature on the settlement sector in Canada has noted a number of barriers to newcomer's economic integration (Banerjee \& Phan, 2014; OCASI, 2012; Shan, 2009). Increasing migration to rural areas is also becoming a concern, particularly because of the lack of support infrastructure set up to accommodate them, due to previously primarily urban migration (OCASI, 2012). The challenges to providing strong services have largely been attributed to limited funding, inefficiencies caused by bureaucracy, and intense competition in the settlement sector (Mukhtar, Dean, Wilson, Ghassemi \& Wilson, 2016). The current settlement model places non-governmental settlement agencies at the front of service delivery, with program funding primarily provided federally through Immigration Refugees and Citizenship Canada (IRCC). The current model heavily relies on private sector strategies, which uses competition among service providers to lower the cost of programs, and rewards larger agencies who can provide services to more clients (Evans \& Shields, 2014; 
Osborne, 2006). The devolution of public service delivery from the national level to lower levels of government and to nonprofit organizations has been a trend throughout the industrialized world since the 1990s (Acheson \& LaForest, 2013). Policy and program design in all areas has largely been influenced by neoliberal practices throughout, and in immigration policy this has meant a political shift towards fewer supports. Shields at al. (2016) noted the following global trends: reduction and restriction of welfare services to immigrants; holding immigrants accountable for their own integration, and limiting access to migration through increased security and bureaucratic racism.

This study argues that the complexity of settlement and integration does not benefit from this by-the-numbers approach, with some programs and agencies being unable to adequately address the diverse needs of many newcomers. There is a strong body of literature that expresses the concerns and recommendations of these government-funded settlement agencies, many of whom have called for a restructuring of the settlement model that reduces intra-sector competition, eliminates administrative inefficiencies, and prioritizes client outcomes over the numbers (Ashton, Pettigrew \& Galatsanou, 2016; Mukhtar, et al., 2016). These challenges are multiplied for smaller ethno-specific agencies or community organizations, who have to compete for a scarce resource pool against larger more established organizations who have greater capacity to compete for funding (Couton, 2014; Sadiq, 2004). Ethno-specific organizations are those which represent and primarily serve one ethno-cultural group and often receive fewer resources than mainstream or multi-service agencies which can attract more clients (Couton, 2014). The result has been the closure of some of these smaller community-based organizations, which is problematic for immigrants as they can provide many benefits that the larger multiservice agencies cannot (Sadiq, 2004; Jimeno, Urquhart, Kilito, Kilito, 2010). The value of community-level planning and local responses to service needs are starting to be recognized, and there is a call for policy interventions that work from the ground up so that solutions can be based on the specific needs of diverse areas and communities (Burr, 2011).

There are also many organizations and institutions that are not part of the formal settlement sector, or are not mandated to provide federally-funded settlement services, which are playing a significant role in providing support to newcomers. Educational institutions, faithbased organizations, and municipal departments, for example have recognized that many of those whom they serve may be newcomers to Canada, and thus they have to be able to respond to the 
unique needs of people who may not speak English, may not have Canadian credentials, or simply be unfamiliar with navigating basic services in their new cities. Many grassroots initiatives and organizations are making an impact, and in many cases filling gaps where formal or "direct" settlement services are lacking. Grassroots and community-level organizations share similar advantages to the ethno-specific organizations described in the literature in that they work closely and personally with the people whom they seek to serve, and in many cases these may be different terms for the same types organizations (Couton, 2014; Sadiq, 2004).

This study has brought to attention the prevalence and value of many grassroots organizations who do not provide direct settlement services, but whose work is integral to immigrant success and integration. Informal and grassroots actors have a level of flexibility that federally-funded service agencies do not. There is a call from governments, academics and settlement workers for "innovation" in settlement and integration services, in order to support improved outcomes for newcomers (OCASI, 2012; IRCC, 2017). This innovation is not necessarily going to come from policy-makers, but potentially from community-level actors who have direct contact with newcomers, and are first in understanding the dynamic and complex situations on the ground, in different communities. It is important to acknowledge that different immigrant and host communities have different needs, and that newcomers even within Canada reside in different economic, geographic situations, and political contexts. The community context is important because this is where integration truly happens, not on a national scale, but through comfort and acceptance in the neighborhoods that people live and work. Community actors on the ground have acknowledged this. Similar to ethno-specific settlement agencies, many grassroots initiatives have been started by immigrants themselves, who are familiar with the unique needs of their communities or else understand from their own experiences what types of supports are most helpful. They may not all serve a specific demographic, but they are catering to needs that they themselves identify with and have the knowledge or the capability to address.

Four non-profit organizations and one municipal worker in the Greater Toronto Area were interviewed about their programs, challenges, and their view of what the needs are for the newcomers they serve. None of the immigrant-serving organizations interviewed in this study were funded by IRCC but instead received their funding through a mix of sources, including provincial or municipal grants, private sponsors, and fundraising. While funding posed 
challenges to all these organizations, the most common issue being limited capacity to sustain and grow their organization, they also had more freedom to run programs that may differ from the federal structure, without the accountability to IRCC that constrained many formal agencies (Mukhtar et al., 2016). The study aims to explore the work and impact of these grassroots and community-based initiatives. Also, in learning about the challenges they face and the kinds of supports and policy changes need to help grow these initiatives, the settlement sector and governments can be better equipped to support and to learn from the work that is taking place on the ground. The goal of this project is to provide research on practical solutions to immigrants' current settlement needs by considering the potential role of grassroots organizations and institutions outside of the formal settlement sector. The study aims to provide insights on the specific contributions and challenges faced by grassroots and community organizations serving newcomers in the Greater Toronto Area (GTA), and contribute to knowledge-sharing in the sector. To accomplish this the study asks: What do some grassroots and community organizations in the GTA see as the limitations and gaps in available public services for newcomers, and what distinctive service offerings or specialized knowledge can contribute to improving these services, both in the formal settlement sector and in the grassroots? Additionally, the study seeks to learn what challenges these grassroots and community organizations face in continuing and expanding their services and how they can be better supported in their work.

This MRP will first provide an overview of the formal IRCC-funded settlement sector in Canada and critiques of the current federal settlement model. It will then detail current issues for newcomers to Canada and for service providers and discuss the roles of various types of organizations, including the informal or grassroots settlement sector. The theoretical basis for and methodology used for conducting the research will then be detailed. Finally, the research findings from interviews with study participants, and the analysis of the research will be presented. 


\section{Chapter 2. Literature Review \\ Overview of the Formal Settlement Sector in Canada \\ The Federal Settlement Model: Government to Governance}

Settlement services in Canada have endured a long history of political instability (Vineberg, 2012) and scholars have noted a number of challenges for these organizations due to budget cuts, administrative requirements, and increased competition in the sector largely as a result of changes made in the mid-1990s (Mukhtar, et al., 2016; Acheson \& Laforest, 2013). In 1995, the federal government downloaded provision of settlement services to the provinces that were able to enter into special agreements with the federal government, in part to alleviate pressures on the budget for the federal department of Citizenship and Immigration (Vineberg, 2012). This funding arrangement between the federal and some provincial governments and immigrant settlement agencies limited these agencies in their ability to invest in innovations and long-term planning, and to adequately serve all their clients (Ashton, Pettigrew, \& Galatsanou, 2016; Mukhtar et al., 2016; Sadiq, 2004). More recently, Canadian municipalities have taken on more of this responsibility, a necessity due to the implications of increased immigration to their communities, including housing and employment needs and supports for social integration, particularly in cities receiving disproportionately high numbers of immigrants (Guo \& Guo, 2016; Rose \& Preston, 2016). Some of the other major issues that have been identified for immigrant settlement include: addressing services and employment in response to changing residential locations of newcomers; discrimination in employment; availability and access to healthcare; lack of housing and affordable housing; political participation and social inclusion for newcomers (Ashton et al.; Mukhtar, 2016; OCASI, 2012; Richmond \& Shields, 2005; Sadiq, 2004; Vineberg, 2012).

Multiculturalism was adopted as an official policy in Canada in 1971, and throughout the 1970s the federal government increased funding for settlement services with the goal of encouraging immigrant integration and fostering interaction between cultural groups (Acheson \& Laforest, 2013). The Immigrant Settlement and Adaptation Program, and employment and orientation programs were created, and the Secretary of State under the Citizenship Branch and the Multicultural Service Program Grant offered operational grants and funding to service provider organizations (SPOs) for infrastructure development. Immigrants began to organize, 
primarily forming organizations representing and serving their own ethno-cultural groups, and began to make an impact in mainstream institutions. There was core funding available for these organizations, and federal programs dedicated to fostering individual and collective participation of new Canadians (Acheson \& Laforest, 2013). Umbrella organizations like The Ontario Council of Agencies Serving Immigrants (OCASI) were formed throughout Canada during this period, acting as a collective voice for SPOs, thereby able to lobby among high levels of government (Acheson \& Laforest, 2013; OCASI, 2018). They called for greater access to services, more equitable allocation of funding and representation in the policy formation surrounding immigration (Acheson \& Laforest, 2013).

By the early 1980s, however, politics brought the multiculturalism program into question by the Canadian public. Previously the main source of funding for citizenship-building programs and for specific ethno-cultural grassroots organizations in immigrant communities, distributing over \$20 million in grants, the program lost much of its budget and was moved from IRCC (then, Citizenship and Immigration Canada) to the Department of Canadian Heritage (Acheson \& Laforest, 2013). It has since been juggled between IRCC and Canadian Heritage serving different mandates, but today functions in funding multicultural events, public education, international engagement, and support of federal and institutional initiatives, with grant contributions of about 6.8 million in 2010, and 4.2 million in 2009 (Government of Canada, 2012; Griffith, 2015). The populist rhetoric of the 1990s and the broader neoliberal discourse further disavowed the policy, instead calling for the promotion of a "national" culture (Acheson $\&$ Laforest, 2013). The public perception of immigrants has a significant impact on the amount of government funding that is available to SPOs. OCASI (2010) recognizes that governments are sometimes faced with negative perception of immigrants by the public, particularly in regards to funding for immigrant services, and often due to misconceptions about immigrants, sometimes incited by politicians themselves. Canada's limitations on settlement spending and professionalization of the sector in part represents the dominant view in the West that much of the burden of integration should fall on the immigrant and not the state (Ko, 2017). This sentiment, along with the lack of beneficial outcomes of some immigrant settlement programs, including high unemployment rates or challenges with language and social engagement puts the federal government under pressure to reduce the costs of settlement programs (OCASI, 2010). 
The ideas of New Public Management (NPM) for cost reduction and efficiency in service provision took root, and by the late-1990s the Ontario Ministry of Citizenship and Immigration under the Harris Conservative Government withdrew completely from direct delivery of settlement services, devolving the responsibility to lower levels of government and to local actors, while there were also reductions to federal funding (Acheson \& Laforest, 2013; Mukhtar et al., 2016). It was during this period that the NPM approach became widespread in the settlement sector. Community organizations lost core funding and began operating through contracts and purchase-of service agreements with the government (Acheson \& Laforest, 2013; Evans \& Shields, 2014; Mukhtar et al., 2016). The influence of neoliberalism in order to address inefficiencies during this period created a free-market structure to public service delivery, and a shift away from the ideals of the welfare state (Evans \& Shields, 2014; Shields, Drolet \& Valenzuela, 2016; Trudeau \& Veronis, 2009). NPM aims to mirror the structure of the capital market, with emphasis on financial efficiency in the provision of public services. However, while private corporations value their outputs in profits, the success of the public service sector, including settlement services, cannot be measured the same way. Brodkin (2011) states that NPM, as a decentralized form of management holds an implicit claim to political neutrality, but argues that this belief is misguided. Defining the desired outcomes for public service organizations which NPM's performance metrics aim to quantify are a highly political issue.

Since the 1990s, the Canadian government has been implementing these principles of NPM and undergoing a structural change from government to governance through devolving responsibility for social services from the state to lower levels of government and to local actors (Acheson \& Laforest, 2013; Richmond \& Shields, 2005). This is a global trend that has affected immigration policy among most major receiving countries (Shields, Drolet \& Valenzuela, 2016). Shields at al. (2016) provide a cross-national perspective on settlement policy in immigrantreceiving nations, surveying Australia, the US, and 11 European countries. The similarities that emerged included the following: the downloading of public services to subnational jurisdictions and non-profit organizations, while holding immigrants more responsible for their own settlement; the reduction of welfare services and often restricted access for newcomers; and an emphasis on competition and financial accountability for service providers (Shields et al., 2016). Public services have thus been increasingly privatized in developed states and influenced by the principles of NPM (Evans \& Shields, 2014). 
Siemiatycki and Triadfilopoulos (2010) state that the role of sub-national governments in immigration has increased internationally, and there is increasing participation of states and local governments in immigration decision-making. Further, they note that decentralization of governance is happening across multiple policy fields, including immigration. IRCC's process of devolving delivery and funding responsibility of immigrant services mirrors that of many other immigrant-receiving countries, such as the US, Australia, and European countries (Shields at al., 2016; Siemiatycki \&Triadfilopoulos, 2010). In fact, subnational governments have also taken up roles in immigrant selection, deportation, legislation of civic rights of newcomers, and "setting the tone of newcomer integration" (Siemiatycki \& Triadfilopoulos, 2010, p. 22). However, the authors found that in situations where responsibility was devolved to lower levels of government but without adequate federal funding, the result was poor service provision. In the United States, for example, there is no systematic strategy for immigrant settlement, and the federal government has a very limited role in direct immigrant services which resulted in both social and economic costs for the nation. They found that immigrants had lower levels of language acquisition, income and naturalization, compared to Canada (Siemiatycki \& Triadfilopoulos, 2010). The recommended model for effective service delivery is a balance of local decisionmaking and the involvement of community partners, with enough federal funding support. The involvement of multiple stakeholders and bottom-up program development would theoretically allow for more flexible and thus relevant programming (Siemiatycki \& Triadfilopoulos, 2010). While the authors recognize the relative strength of Canada's settlement model, this ideal structure has not been fully realized in Canada.

Despite growing provincial and municipal roles in settlement, the federal government has decision-making power in regards to immigration to the provinces, with the exception of Quebec. Prior to 2013 and 2014, the provinces of British Columbia and Manitoba respectively had full jurisdiction over immigration and settlement in their provinces. However, as part of IRCC's goal to attain uniformity and improve information-sharing, this model was foregone in favour of a centralized decision-making structure (IRCC, 2017). This federal emphasis on standardization and accountability extends to the non-profit settlement sector where strict bureaucratic controls places significant strains on SPOs. Organizations that are dependent on government contracts are also limited in their use of funding, as funding contracts specify the service or program that the money can be used for, the client group that can be served and the 
quantitative outcomes that should be measured in order to determine the program's success (Mukhtar et al., 2016). A major concern for settlement service providers are the client criteria, as IRCC funding requirements limit most programs to permanent residents, excluding refugee claimants, temporary foreign workers, international students, or those who otherwise do not have legal status in Canada (Ashton et al., 2016). However, studies have noted that some organizations do not turn people away because they are ineligible, but simply operate off the books, not claiming staff time and other costs associated with programming, or else seek private funding or refer clients to organizations who are privately funded (Trudeau and Veronis, 2009). This is one key example of the inefficiencies of this bureaucratic funding model and supports the notion that many of the policy mandates are out of touch with the realities on the ground.

The difficulties for organizations operating under this model are two-fold. First, SPOs are unable to invest in long-term strategic planning, in-depth evaluation and needed changes to programming. Secondly, administrative requirements to satisfy funders are costly and timeconsuming. One of the major challenges occurs when government-mandated performance measures are not relevant to what is happening at ground level (Evans \& Shields, 2014). This top-down approach can become a hindrance rather than a mechanism for ensuring effectiveness. Brodkin (2011) voices the concern that in models of NPM staff may cope with these measures through practices meant to "meet the numbers," sometimes sacrificing client outcomes to achieve this. Türegün (2013) suggests that some of the challenges that the settlement sector faces today can be attributed to its lack of professionalization. Despite the long tenure of formal immigrant settlement supports Canada, the sector today still has no legal jurisdiction (Türegün, 2013; Vineberg, 2012). In terms of professionalism, settlement work is only recognized within the broader field of social service work, and to this day relies heavily on volunteers, with minimal training for workers. Additionally, short-term contractual funding causes job instability within the sector, and limits the work that settlement workers are able to do in terms of program delivery (Türegün, 2013). Brodkin (2011) talks about the very significant impact that organizational resources have on individual agency within organizations. A 2017 report by IRCC evaluating the Settlement Program stated that $42 \%$ of SPOs have between 1 and 5 full time equivalent employees (FTE) providing IRCC-funded settlement services, 19\% between 21 and 50 FTEs, and $9 \%$ with more than 50 , while $79 \%$ of SPOs use volunteers to support the provision of services (IRCC, 2017). While acknowledging the concerns with professionalism as a system 
of inequality and stratification based on specialized knowledge, Türegün (2013) proposes under the sociology of work approach coined by Abbot (1988), that technical terms of work are key to establishing a form of jurisdiction. Türegün argues that this jurisdiction contributes to the relative stability of professional fields such as education and healthcare. While not acknowledged by government under NPM, the provision of services to new immigrants is a form of specialized work, and the expertise required for it is valuable.

\section{Government-Funded Programs and Services}

Immigration, Refugees and Citizenship Canada (IRCC) funds the majority of direct services and programs for immigrant support in settlement. Projects funded by IRCC operate on three-year funding contracts after a national call for proposals (IRCC, 2017). According to IRCC (2017) federally-funded services can be divided into three streams: direct service delivery, support services and indirect services. The direct services stream funds SPOs to deliver programs under six main areas: needs assessment; information and orientation; language training; translation; employment services; and Community Connections (which matches newcomers with people in their neighborhoods, peer support groups, and community events). These services are available without charge to permanent residents of Canada (IRCC, 2017).

IRCC also funds support services, which are meant to assist immigrants in accessing settlement programs, such as childcare, translation and interpretation, transportation, disability support and crisis counseling. These services are expected to comprise more than $20 \%$ of funding for direct services within a contribution agreement. The final category, referred to as indirect services, is geared towards supporting partnership development, capacity building and the knowledge-sharing between SPOs. IRCC states that this funding should support research, develop innovative practices, or fund updated training. Local Immigration Partnerships, for example, are one of the most significant products of indirect service funding (IRCC, 2017).

Until 2008, IRCC primarily funded newcomer settlement and integration services through three separate streams: language instruction; Immigrant Settlement and Adaptation Program, which provides assistance in employment, housing, information, etc., and supports research within the settlement sector; and Community Connections (previously, the Host Program) which funds place-based initiatives, such as Library Settlement Partnerships, Settlement Workers in 
Schools and In-School Supports (Burr, 2011; Government of Canada, 2018; Lim, Lo, Siemiatycki, and Doucet, 2005). After a 2004 review of these programs revealed a number of issues with the federal settlement model, these three streams were consolidated into The Settlement Program in 2008 (Government of Canada, 2018; Neodorf, 2016). While maintaining a decentralized approach in which community organizations are the primary service providers funded through IRCC, the new model was meant to address some of the major concerns within the sector. First, The Settlement Program was meant to have performance measures more aligned with outcomes, rather than outputs such as number of clients served, as was previously the case (Neodorf, 2016). These private-sector efficiency measures often hindered non-profit settlement agencies from providing consistent and effective programming to their clients (Brodkin, 2011; Evans \& Shields, 2014). As organizations often applied for funding under multiple streams under the previous model, the new model also aimed to consolidate programs, reducing the administrative burden of multiple applications and accounting reports. With this program there was an increase to three-year contribution agreements, as well as incentives for collaborations in planning and service delivery between organizations (Neodorf, 2016). Addressing the challenges that motivated this change, however, is still a work-in-progress with many settlement organizations claiming they still struggle with contract limitations and inadequate funding, particularly a lack of core funding for daily operations (Evans and Shields, 2014; Mukhtar et al., 2016; Türegün, 2013).

According to IRCC, there are many cases where provinces provide funding support for settlement services, in cases where newcomers are ineligible under federal parameters (IRCC, 2017). In Ontario, for example, the Newcomer Settlement Program (NSP) is funded by the Ontario Ministry of Citizenship and Immigration (MCI), and fills some of the gaps left by the federal streams. Whereas federal newcomer programs will pay for those who have been in Canada for less than three years and who are not citizens but have some form of legal status, NSP covers newcomers up to five years after arrival and includes refugee claimants, permitholders, permanent residents and citizens (Ontario, 2012). In addition to NSP, Ontario supports bridge training programs, youth programs, language interpretation, and projects aimed at supporting the non-profit sector. Foundations and the private sector also provide funding support to immigrant-serving organizations. The 2005 Canada-Ontario Immigration Agreement led to enhanced funding for settlement and integration services, expanded programming, co-funded 
bridge training projects, increased professionalization of the settlement sector, and greater inclusion of municipalities, particularly Toronto (Rose \& Preston, 2005).

\section{Evaluation of Canada's Settlement Program}

The Settlement Program is the largest federal grant and contribution program for the support of immigrant settlement and integration, and IRCC noted an increase in demand for services over the past few years (IRCC, 2017). In a 2017 evaluation of the Settlement Program, IRCC stated that the program was effective in meeting their expected outcomes (IRCC, 2017). However, a number of scholars and practitioners have expressed concern with increasingly negative outcomes for long-term integration of immigrants, particularly in regards to the goals of fostering belonging and societal engagement (Mukhtar et al., 2016; Omidvar \& Richmond, 2003). According to IRCC, they found in their evaluation that employment-related services had the greatest impact in terms of improving language skills and providing knowledge of the Canadian labour market. In contrast, Language Training, Information and Orientation, and Community Connections provided weaker results (IRCC, 2017). Those who gained the most benefit from IRCC-funded services were economic immigrants and immigrants with higher levels of education and English proficiency upon arrival in Canada (IRCC, 2017). This raises concerns about how services are catering to immigrants from other streams, or who have lower levels of education or language proficiency.

IRCC (2017) also identified a number of areas that needed improvement, including the ability of services to cater to different demographics and individual needs such as mental health issues. They also noted particular concerns with the effectiveness of Language Training. Overall, IRCC noted a need for supports that would enable immigrants to access available services, including mainstream community services that are not funded by IRCC. They noted a need to strengthen data on service outcomes with an ongoing survey to clients and non-service users. The results of the study also raise the question of accessibility, with roughly $39 \%$ of newcomers having accessed at least one IRCC-funded Settlement service in their first two years in Canada. This leaves $61 \%$ of newcomers who did not access services in this time frame. While some may have voluntarily chosen to forgo the use of formal services, it is likely that there were many in need of services who were unaware of their existence or else unable to access services due to 
barriers such as transportation, work hours, or language constraints (IRCC, 2017). There is also the possibility that eligibility restrictions prevented many newcomers from accessing services due to their immigration status, or else that the specific services they needed were not available to them in their area. A survey of client outcomes showed that many clients of IRCC-funded services also used alternate supports, whether getting help from friends and family, informal training, internet research, or community events (IRCC, 2017).

IRCC found variation in service access among specific demographic groups. $72 \%$ of refugees used settlement services in their first two years in Canada, compared to $31 \%$ of economic immigrant principal applicants. Family class immigrants were also noted to have a particularly high need for services. Interviews of settlement staff indicated that vulnerable populations, i.e. those experiencing trauma, mental health needs, isolation or language barriers, had a greater need for services (IRCC, 2017). There were varied opinions on the length of eligibility for services, in which immigrants are ineligible once they qualify to apply for citizenship. Some participants believed that the service window was too short, while others felt it should remain only three years so as to "not [be] unfair to Canadian citizens that are not provided with the same suite of services" (IRCC, 2017; IRCC 2017, p. 19). Scholars have noted, however, that the eligibility criteria of the Settlement Program limit the types of programs that can be funded as well as the clients who can be served, based on their citizenship status and length of time in Canada (Mukhtar et al., 2016; Trudeau \& Veronis, 2009). These restrictions leave out many newcomers who are in need of support, including temporary foreign workers, asylumseekers and new citizens. Moreover, many great programs are not eligible for funding because of the inflexibility of the federal criteria (Siemiatycki \& Triadafilopoulos, 2010). Some settlement workers have claimed that this arbitrary segregation of immigrants who qualified for services, and those who did not, went against their principles of serving those in need of support. But IRCC is restricted by the rules of the federal Treasury Board, which are based on the idea that Canadians would not want to pay for those who may not permanently stay in the country (Ashton et al., 2016).

Sixty-three per cent of SPOs in the study indicated that they received funding from sources other than IRCC. $40 \%$ of this alternate funding was used to serve clients who were not eligible under IRCC restrictions, while 51\% was used for both non-eligible clients, while also filling funding gaps for eligible clients (IRCC, 2017). IRCC called this a "complementarity" of 
federal and provincial funding, suggesting that provincial funding was serving its intended role in filling gaps in federal funding (IRCC, 2017, p.21). However, extensive literature notes the difficulties that this funding structure causes for immigrant-serving organizations. Firstly, the narrow eligibility requirements can mean that SPOs must either turn away people in need of help, or else serve them unofficially, which places strain on staff and organizational resources (Ashton et al., 2016). Additionally, the fact that some alternate funding is used for eligible clients supports the literature in suggesting that federal funding is not enough even for serving permanent residents. The need to seek alternate funding provincially or through private sponsors contributes to an already heavy administrative burden for many SPOs. IRCC also noted a number of clients through IRCC Needs Assessment and Referral Services who identified "nonIRCC program needs," or who needed services that were not federally-funded and thus were referred to other available community services (IRCC, 2017).

\section{Ethno-Specific and Community Organizations}

In 2010, the Ontario Council of Agencies Serving Immigrants (OCASI) released a report in response to the modernized settlement approach that was then in the process of being implemented by Citizenship and Immigration Canada (CIC). In discussing the outcomes that they hoped to see from the remodel, OCASI placed heavy emphasis on looking at policy in terms of how it will be implemented in practice. They noted the need for programs and services to be tailored to specific demographic characteristics, acknowledging the unique and intersectional experiences created by factors such as age, immigration status, language ability, education, gender, sexual orientation, ability, race, ethnicity and residential location (OCASI, 2010). Scholars have noted the strengths of ethno-specific organizations in being better equipped to serve the unique needs of their communities, and the ability of small community organizations to respond with more flexibility and innovation than the larger SPOs (Jimeno, et al., 2010; Sadiq, 2004). The inflexibility of the current federal model, however, poses a challenge to these organizations.

Sadiq (2004) observed that Ontario newcomer services operate under a "two-tier" system of dependency, in which the federal and provincial governments provide settlement funding mostly to larger multi-service agencies to deliver specific programs. Small organizations are 
often seen as less favorable for government contracts as they are not able to demonstrate the same capacity or serve the same scope of clients. They also may lack the administrative capacity to undergo the process of applying for many competitive contracts (Sadiq, 2004; Jimeno, et al., 2010). Jimeno et al. (2010) in their study of ethno-specific organizations in Ottawa, demonstrate why it is crucial that these organizations are able to remain in operation and increase their capacity. Aside from being more receptive to the needs of specific immigrant groups, because they are often not fully restricted by IRCC mandates, ethno-specific organizations are able to provide programs that address the long-term process of integration rather than simply tackling short-term settlement needs. Workers at these organizations identified some of their clients' concerns, for example: the desire to preserve cultural values and practices; the challenges with the changing roles of men and women caused by migration; or adjusting to the different norms associated with the individualist culture of Canadian society (Jimeno et al., 2010). These organizations provide culturally-relevant services, including orientation, information and accompaniment, and appropriate cultural supports, often serving to connect newcomers to other community members or to mainstream services. Whereas government-funded mainstream services often do not have a cultural understanding of how to serve many newcomer communities, small community organizations do not have the resources to fill gaps in direct services. Ethno-specific organizations are instead able to provide services to their community in their own language and culture, and have networks, personal connections and trust within the communities that mainstream organizations do not have. It is clear that strong partnerships are needed between these two levels of service, but for this to work there must be equal sharing of resources, mutual understanding, and willingness of workers in mainstream organizations to respond appropriately to the needs of culturally diverse clients (Jimeno et al., 2010)

Stakeholders in the settlement field have proposed best practices for SPOs in providing effective newcomer services. These suggested practices are largely in response to limited resources in the sector, and recommend standardization in order to increase effectiveness (Burstein, 2010; Jimeno et al., 2010). This is important as many funders are using this language of "best practices" when assessing an organization's potential for grants, but the widely accepted outline of best practices can exclude small ethno-specific organizations because they are created by funders and mainstream organizations. They therefore may be the result of assumptions that do not reflect the realities of the communities they seek to serve (Jimeno et al., 2010). For 
example, the ability of an organization to demonstrate accountability and professionalism is dependent on the organization taking on a Western non-profit model, with a Board of Directors, specific administrative and operational measures, etc., and which can be very challenging for small groups with limited financial resources and staff capacity (Jimeno et al., 2010). Certain programs or services may be disregarded by funders, because of a Western understanding of what is seen as acceptable. As an example, the authors refer to programs for children under a certain age, which may disregard a mother with children of different ages who is accustomed to keeping her children together. Best practices also emphasize "empowerment" of clients, which does not have the same applications in all cultures. The exclusive promotion of client autonomy and empowerment may cause tensions if the value of collectivism in some cultures is ignored, and this mindset might disregard the strengths of a united community (Jimeno et al., 2010).

These best practice solutions to resource limitations often propose ways for organizations to "build capacity." These include learning strategies for writing more competitive funding applications, and often talk about partnerships. These recommendations might be disregarding the precarious position of some of these smaller organizations who may not have the administrative capacity to apply for multiple grants, or may not provide the programs that would entitle them under the strict requirements of funders. Such recommendations may also disregard the difficulties in seeking partnerships with larger organizations, who are themselves often faced with scare resources, and whose mandates may compromise the independence of these ethnospecific organizations (Jimeno et al., 2010; Sadiq, 2004). Given the need for creative ways to address dynamic immigrant needs and the call for innovation in the sector (OCASI, 2012), these challenges for smaller organizations must be considered. The inflexible and market-centric structure of government funding should be reconsidered, and barriers to new and smaller entrants in the settlement sector must be removed, particularly for smaller or ethno-specific organizations. Working closely with immigrant communities, thus better in touch with the needs of immigrant communities, these community organizations have valuable knowledge to bring to the settlement sector and should be supported as equal contributors. 


\section{Current Issues in Newcomer Settlement and Integration Economic Integration}

A 2012 study, Making Ontario Home (MOH) by the Ontario Council of Agencies Serving Immigrants (OCASI) provides a comprehensive overview of settlement services in Ontario. The study contained survey responses from 2530 immigrants who had arrived in Ontario between 2000 and 2010, with 158 countries represented. Survey responses were gathered from refugees, refugee claimants, migrant workers, and those without legal immigration status, while focus groups and interviews were held with settlement service providers. The study asked about use of services, satisfaction with the type of services, satisfaction with providers and service types, and challenges with accessing services. They sought to understand which immigrant and refugee needs were being met, where were the service gaps, and the reasons some immigrants did not use services (OCASI, 2012). This study identified finding employment as the highest concern for immigrants in Ontario, with almost $62 \%$ of respondents stating this was the most important concern. OCASI and other stakeholders in the immigrant-serving sector recognized that "economic integration is critical to the social and political integration of immigrants" (OCASI, 2010, p. 3). Settlement providers also emphasized the fact that newcomers level of need in terms of overall settlement is closely related to whether or not they are able to find adequate employment (OCASI, 2012).

It is crucial that there are effective and accessible employment services for newcomers and the MOH study showed that there is ample room for improvement. While about $60-70 \%$ of survey respondents expressed overall satisfaction with various employment services, only about $32 \%$ said that IRCC employment and skills training helped them find employment. A much higher percentage, 58\%, said that the training had helped them understand the "culture" of the Canadian workplace. Only about $20 \%$ said that the services helped them to find work that matched their skills or education, with another $20 \%$ stating that they were help with getting their credentials recognized in Canada (OCASI, 2012). While OCASI placed heavy focus on immigrants' difficulties with accessing services, for example due to transportation costs or hours of service, the outcomes for those who did access services speaks clearly of need to reassess the programs themselves. The need for continued improvement, particularly in regards to 
employment services, is supported by research on overall economic outcomes for newcomers to Canada.

According to Burstein (2010) high poverty rates among immigrants, particularly visible minorities, is a serious concern in and around major cities. This "racialization of urban poverty" has been called a threat to Canada's social stability (Shields, 2002 as cited in Omidvar \& Richmond, 2003, p.2). A 2017 report by Statistics Canada noted chronic low-income among Canadian immigrants as an issue since the 1990s. Low-income was defined in this report by a variation of the Low Income Measure (LIM), by which the low-income cutoff was set at half of the median income of Canadians, adjusted by region to account for variations in cost of living throughout Canada (Picot \& Lu, 2017). Chronic low-income was defined as five or more consecutive years below this LIM, and recent immigrants defined as those who had lived in Canada for five years or less. The report stated that while the low-income rate decreased among the Canadian-born during the 1990s, the rate increased among newcomers overall, resulting in a low-income rate among recent immigrants that was 1.4 times higher than that of the Canadianborn in 1980, 2.5 times higher in 2000, and 2.7 times higher by 2010 (Picot \& Lu, 2017).

Picot \& Lu (2017) also noted that economic conditions varied across cities and regions, impacting earnings and low-income levels. They suggest that economic integration may be more difficult in cities that attract large numbers of immigrants, such as Montréal, Toronto and Vancouver, even if they have a strong economy. Levels of social assistance as well as other policy differences also play a role, particularly with traditionally immigrant-receiving areas like downtown Toronto having stronger settlement infrastructure than urbanizing areas around the GTA (OCASI, 2018; Picot \& Lu, 2017; Sadiq, 2004). The communities that had very little improvement in the chronic low-income rates among immigrants between 2000 and 2012 were almost all located in southern Ontario, including Oshawa, Toronto, Hamilton, St. CatharinesNiagara, Kitchener, Guelph, London and Windsor (Picot \& Lu, 2017).

Picot \& Lu (2017) noted significant differences in low-income levels among demographic groups. Age was the most significant factor in 2012, with immigrants over 65 having the highest rates of chronic low-income, at 50\%, compared to a chronic low-income rate of Canadian-born seniors of only $2 \%$. In the same year, immigrants from Northwestern Europe, the Philippines, Australia, New Zealand and the United States had rates between 4\% and 5\%, while those from East and South Asia had rates four times higher, between 17\% and 19\% (Picot 
\& Lu, 2017). Controlling for differences in education level and official language proficiency at landing, immigration class, and years and geographic location in Canada, place of birth still accounted for $75 \%$ of the difference in low-income rates (Picot \& Lu, 2017). In 2012, there was almost no difference in chronic low-income rates by education level at landing. Adjusting for other characteristics the rate of chronic low-income for those with only secondary school education was only 1.1 times the rate for those with a non-university postsecondary education. The rates for those with trade, university and postgraduate education upon landing were all just over $10 \%$, while the rates for those with secondary school education or less were at around $14 \%$ (Picot \& Lu, 2017). According to Somerville \& Walsworth (2009), the greatest difference in low-income rates between the Canadian-born and recent immigrants was among university graduates, particularly those with engineering and applied science degrees, professions which offer some of the highest incomes in the Canadian labor market. Regulated professions and trades account for upwards of $20 \%$ of the Canadian workforce, and the requirement for Canadian certification to enter many of these jobs puts immigrants at a disadvantage (Shan, 2009). As a result, skilled immigrants in regulated professions experience more significant occupational downgrading upon migration than those in unregulated work (Banerjee and Phan, 2014). These findings allude to the prevailing issue of underemployment among immigrants, due largely to lack of credential recognition and other barriers to professional work in Canada, and also raises concerns about discrimination and other structural barriers to labour market entry (OCASI, 2012).

This trend of negative employment outcomes for immigrants has been increasing, with many studies showing that they attain lower wages generally than Canadian-born workers, and face layers of barriers to professional work (Banerjee \& Lee, 2012; Jimeno et al., 2012; Somerville \& Walsworth, 2009). Studies also show that racialized immigrants experience worse outcomes in terms of employment and wages than their white counterparts (Statcan, 2016; Banerjee, 2009; Shinnaoui \& Narchal, 2009). The fact that many immigrants experience occupational downgrading upon arrival in Canada has been attributed to lack of English proficiency, visible minority status, and lack of Canadian education (Shinnaoui \& Narchal, 2010; Banerjee \& Lee, 2012). Visible minority immigrants face a higher disadvantage in two ways: firstly, upon arrival in Canada, starting income for visible minority immigrants is lower than that of European immigrants; secondly, while Europeans experience accelerated income growth 
within a few years to achieve similar income to the Canadian-born population, visible-minorities tend to have slower rates of growth, so that many are unable to catch up to Canadian-born wages within their lifetime (Banerjee, 2009). Couton (2014) notes that many low-wage business sectors have become enclaves for racialized immigrants, for example about half of taxi drivers in Canada's major cities, including Montreal, Ottawa and Toronto, are from a specific immigrant background (Couton, 2014). Many new immigrants are forced to work in low-wage "survival jobs" due to limited opportunities. This type of work allows little time and insufficient financial resources for them to learn English or get skills training, thus creating a cycle of poverty that is at best extremely difficult to escape (OCASI, 2012).

These economic outcomes point to a broader issue of barriers to immigrant integration into Canadian society. There is a contradiction in policies that emphasize the need for new immigrant workers to support the Canadian economy, with approximately $60 \%$ admitted under the economic class, and with programs like the Provincial Nominee Program and Local Immigration Partnerships seeking to attract immigrants (Government of Canada, 2017b; IRCC, 2017), but without the supports and interventions needed to facilitate their full participation. A 2001 study estimated that the underutilization of immigrant skills costs Canada $\$ 1.6$ billion a year (Shan, 2009). Not only does this suggest a need to look at employment supports for new immigrants, it also requires acknowledgment of the impacts of employer discrimination and discounting of foreign skills. This adversely affects Canada as a whole, which loses the full benefits that highly skilled and knowledgeable newcomers can offer.

\section{Social, Cultural and Civic Participation}

The goal of supporting newcomer integration is for them to be fully engaged in the social, economic, political, and cultural life of Canada (Burr, 2011; IRCC, 2017). Integration has been described by policy-makers and scholars as a "two-way street," requiring equal participation of both newcomers and Canadian society (IRCC, 2017; OCASI, 2010; OCASI, 2012). However, the supporters of the "two-way street" concept must acknowledge the fact the immigrants are excluded in many cases, and there is progress to be made in ensuring that Canada is truly an inclusive and welcoming society. 
Inclusion also means removing the barriers caused by attitudes or systemic problems, which may impede an individual's ability to participate (City for All Women Initiative, 2015). These barriers may not be unintentional, but rather built into existing policies, practices, and the assumptions and stereotypes that reinforce them (City for All Women Initiative, 2015). Removing them means changing the one-size-fits all approach when it comes to services, and placing emphasis on making the labour market more accessible, for example through addressing barriers to credentialed professions or cases of unfair hiring practices.

The Social Inclusion Perspective says that in order to allow newcomer participation in all dimensions of life in Canada, racism and prejudice must be addressed in all its forms. This means ensuring all policy recommendations are evidence-based, and advocating towards policy changes that remove systemic barriers (Omidvar \& Richmond, 2003). Immigration has been predominantly to urban areas in Canada, and segregation of ethnic communities within cities has led to the growing phenomenon of the racialization of urban poverty (Omidvar \& Richmond, 2003). The formation of ethnic enclaves can facilitate the development of religious, cultural and community institutions, creating spaces where people can share common cultural interests and form strong social networks. Certain groups, for example, those who are not yet fluent in English, can especially benefit from support from these communities. However, the problem occurs when certain groups are increasingly segregated due to prejudice and exclusion from the broader society, and this segregation often coincides with low-income neighborhoods and poor housing (Omidvar \& Richmond, 2003). A settlement service system that does not acknowledge racism and systemic barriers will be ineffective in combating the persistence of an immigrant underclass (Omidvar \& Richmond, 2003). IRCC initiatives such as Local Immigration Partnerships (LIPs) have more recently placed emphasis on the need to create "welcoming communities," one where newcomers have access to a full range of services, where they are able to participate and are openly received into an inclusive environment (Burr, 2011, p. 2). The effectiveness and accessibility of social supports can have a significant effect on whether newcomers decide to move to and stay in a particular community. Adequate social supports have been shown to enhance social networks and empowerment, facilitate employment, and improve overall health (Burr, 2011).

It is also important to acknowledge the contribution to society that newcomers can make if provided with the resources and opportunities to do so, not only economically, but in a civic and 
social capacity. When they have the ability and resources to share their culture, as employees, volunteers and community members, society as whole gains this benefit. In studying the work of Chinese volunteers in a Vancouver immigrant organization, Guo (2014) demonstrated the value of ethnic diversity in fostering social and civic participation, challenging the stereotype of the passive immigrant. Guo found that Chinese volunteers were brought together through their collective identities as immigrants and that an ethno-specific community organization could provide this space for volunteerism. Volunteering was a means for these immigrants to do something for themselves that would help them to feel more a part of their new communities. Participants felt that volunteering helped them to increase their knowledge of Canada, acquire job skills, and build new social networks. Being a part of the organization in a volunteer capacity also meant helping new immigrants to settle in Canada, helping their community, and building bridges between newcomers and current residents (Guo, 2014). The study is one small example among many which suggests that immigrants can be, and are eager to be, active citizens in more than an economic capacity, if only they are given the opportunities to do so.

\section{Municipal Concerns and Community Infrastructure}

With the changing residential patterns of newcomers who are now locating in more suburban or urbanizing regions than before, SPOs are faced with capacity challenges in these areas where there is less service infrastructure (Mukhtar et al., 2016). The location of available services affects who is able to access them, and spatial mismatch of services to newcomer residences is increasingly becoming a concern (OCASI, 2012; Sadiq, 2004). Immigrants settle unevenly across Canada, which poses challenges for services and infrastructure in highconcentration areas. On the other hand, many smaller municipalities across Canada, not just major receiving centres, have been looking at ways to attract and retain newcomers to contribute to their economy (Burstein, 2010). As of 2017, 48\% of immigrants who received services from the federal Settlement Program listed Ontario as their intended province of destination (IRCC, 2017), with the most popular destination cities being Canada's 33 census metropolitan areas (CMAs) (Guo \& Guo, 2016). More than 60\% of recent arrivals to Canada settled in the three largest CMAs of Toronto, Vancouver and Montreal, which hold more than a third of Canada's 
total population. It is predicted that most new immigrants, especially visible minority immigrants, will continue to choose these larger cities until 2031 (Guo \& Guo, 2016).

However, despite these major cities being the primary recipients of immigrants, tasked with providing adequate housing, employment, education, and social services, they do not have a formal role in developing immigration policies and programs (Guo \& Guo, 2016). Municipalities, particularly those who had not previously experienced high rates of immigrant arrivals, are playing a greater role in coordinating and providing newcomer settlement support, yet they lack the decision-making power, funding and resources to act independently (Guo \& Guo, 2016). While Toronto has a limited consultative role in immigration decisions under the Canada-Ontario Immigration Agreement (Rose \& Preston, 2017), there is still a disconnect between the federal role in immigrant selection and program design with the fact the complex dynamics of settlement and integration at the local level (Guo \& Guo, 2016). Drawing lessons from other settlement models internationally, if the federal government devolves settlement services to municipalities without providing the adequate funding, this will result in long-term costs social costs such as inadequate labour market integration and low rates of naturalization for newcomers (Siemiatycki \& Triadfilopoulos, 2010)

Local Immigration Partnerships, IRCC-funded networks of government workers and community members and organizations, began as an initiative of the 2005 Canada-Ontario Immigration Agreement (COIA) (Burr, 2011). COIA recognized the important role of municipalities with respect to the integration of newcomers in Ontario. Municipalities across the province have identified attraction and retention of newcomers, as well as successful settlement and integration as key priorities. Further, they identified the need to propose new strategies for addressing complex social issues and service gaps and in response LIPs were introduced through COIA (Burr, 2011). In 2008, Citizenship and Immigration Canada established these LIPs throughout the province, and as of as of 2011 there were 45 LIPs in Ontario, including 15 in Toronto neighborhoods (Burr, 2011). The initiative was created largely in response to labour market needs in smaller municipalities and the increasingly limited capacities of traditional destination cities like Vancouver, Montreal and the Toronto core. The push towards higher levels of immigration to these smaller municipalities, through the Welcoming Communities Initiative and other initiatives such as the Provincial Nominee Program (PNP), has driven significant economic growth for some of these regions (Government of Canada, 2017a; IRCC, 2017). 
The Welcoming Communities Initiative was meant to address the factors that according to Citizenship and Immigration Canada (now IRCC), would contribute to a welcoming community: employment opportunities, social capital, affordable housing, acceptance of cultural diversity, and effective newcomer services (CIC, 2013). Another prominent concern over the last decade has been the lack of social infrastructure in these municipalities who have few immigrant supports compared to cities like Toronto, but also more limited physical infrastructure such as affordable housing or religious and cultural centers (Sadiq, 2004; OCASI, 2012).

Committees like LIPs can play an important role in helping municipalities address some of these concerns. They support planning and delivery of newcomers services across sectors, assist in community planning, seek to improve social, economic and civic participation of newcomers, and support labour market access and the creation of "welcoming communities" (Burr, 2011). In 2017, LIPs reported that they were conducting research on community needs and believed that they were having some impact on knowledge-sharing of immigration research (IRCC, 2017). However, many stakeholders also noted that there is greater opportunity for knowledge gained by LIPs to be disseminated throughout the communities they serve, as well as for their research to be considered in policy (IRCC, 2017). 


\section{Chapter 3. Theoretical Perspective The Influence of Neoliberalism on Immigration and Settlement}

The analysis of this MRP is theoretically based on the concept of the neoliberal state, its influence on immigration and settlement, and more broadly on public services in general. Neoliberalism as a policy orientation "is based on the belief in the value of the free movement and accumulation of capital, minimal state intervention in the private sphere of markets and individual rights" (Nihei, 2010 as cited in Shields at al., 2016, p.12). According to Shields at al. (2016), it has resulted in the shrinking of state responsibility in the public domain, and consequently resulted in the shift towards market-based settlement service provision, with less federal support. Thus, according to Shields (2014), the mid-1990s in Canada saw a devolution of support and services from the federal government to sub-national jurisdictions and to the nonprofit sector (Shields et al., 2016). Another influence of neoliberalism and globalization in the field of Canadian immigration was the creation of immigration categories based on human capital value with emphasis on expanding acceptance to migrants from developing countries (Shields et al., 2016). Multiple studies by Hannan, Bauder and Shields (2016); Sassen (1999); and Sassen (1998) note that these policies also involved the acceptance of newcomers to occupy the low-wage, non-professional sectors of the economy as temporary workers and "illegal" immigrants (Shields et al., 2016, p.12). Along the same lines, immigrants under the neoliberal structure are held largely accountable for their own settlement, and are considered for acceptance based on their human capital value. Aliweiwi and Laforest note that services are heavily focused on supporting their economic integration, as opposed to social and civic participation (Shields et al., 2016).

Neoliberal policy has led to a structural change in public services, in the form of devolution of power over services from the state to lower levels of government and to local actors (Acheson \& Laforest, 2013; Richmond \& Shields, 2005). Delivery of services under this structure is largely the responsibility of third party non-profit organizations who are funded by government and foundations through short-term, competitive contracts, based on specific programs dictated by funders (Shields et al., 2016). According to Grey and Statham (2005); and Evans, Richmond and Shields (2005), settlement programs are purposefully underfunded due to market-based logic, which assumes that voluntary and charitable contributions will fill service 
gaps (Shields et al., 2016). However, the majority of settlement organizations in Canada rely heavily on federal funding contracts, and because they are limited and competitive, the government still maintains strict control over how the funding is used, what services are provided, and which newcomers are eligible for support (Mukhtar et al., 2016; Sadiq, 2004). Funders determine the most "efficient" use of money, often out-of-touch with the realities of organizations working on the ground, an arrangement based on neoliberal values of competition and cost reduction (Shields at al., 2016).

Under this current structure, Sadiq (2004) proposes that Wolch's (1990) theory of the "shadow state" is relevant to the settlement sector in Canada. According to Sadiq, the financial dependency of non-profit organizations on the federal government allows the state to maintain control over the public service sector. Sadiq questions whether settlement agencies are able to "democratize the delivery of newcomer settlement services" and advocate for progressive change in immigration and settlement policy, or whether they are unable to exercise autonomy due to government control over their operations (Sadiq, 2004, p. 25). Kim (2016) argues that under the neoliberal mandate, while there is a struggle for non-governmental organizations to exercise "grassroots democracy," there is still opportunity for community organizations to be a space of

resistance. Community service workers and volunteers are independent actors, who maintain the ability to mobilize support, and to "counteract the control of the dominant system in inflected ways." (Kim, 2016, p.110).

\section{Theories of Assimilation and Integration}

The neoliberal approach has often argued that there is inadequate return on investment for newcomer supports, and to raise concern about creating "dependency" on welfare and public services (Shields et al., 2016). The strategy has thus shifted to ensuring immigrant-selection matches the needs of the Canadian labour market, and with that the expectation that newcomers be more self-reliant in supporting themselves. Skilled and educated immigrants, and those in need of fewer supports, are seen as "ideal immigrants" (Ko, 2017; Shields et al., 2016). Those with higher education and English-language proficiency are also valued higher because they are seen to be able to "adapt" better to their new country, and require less investment in settlement services. 
Dubois-Shaik (2014) notes that migration is problematized in discourse in Western European nation-states. Dubois-Shaik references discourses and national policies on immigrant integration in Europe to demonstrate the relationship between the two. In response to controversial political debates on immigration and multiculturalism the narrative of "integration" is often used. The language of migration and integration is translated by politicians and policymakers which creates policy from this discourse. Migrant membership practices in Western European countries is restrictive because of the discourse which problematizes migration, and subsequently, policy which remains exclusive (Dubois-Shaik, 2014). According to Mitchel (2003), the problematization of migration, and of culture, is a platform that serves the neoliberal state, through which the goal is to assure the specific role of migrants in the Western capitalist market (Mitchel, 2003 as cited in Dubois-Shaik, 2014). These problems are defined by those in power, and thus the policy solutions serve those in power rather than those whom they purport to help. Dubois-Shaik (2014) argues that this problematization persists in integration policy and processes through translation into the public sector. The role of educating migrants on the logic of social democracy, with the sole goal of allowing them to contribute to the labour market, may prevent development of social citizenship and restrict the development of individual identity (Dubois-Shaik, 2014). This discourse, however, promotes the idea that immigrants are to blame if they fail to integrate (Shields et al., 2016), and shifts the fault away from a receiving society who exercises discriminatory practices which hinder successful integration.

John Berry (2003) identifies four modes of acculturation, or sociocultural integration of immigrants from minority ethno-cultural groups. In determining these he posed the questions of whether there is value in maintaining one's cultural identity and customs, and whether intercultural interaction is important. The four modes are integration, assimilation, separation and marginalization. Integration occurs when both cultural maintenance and intercultural contact are achieved, assimilation allows for high levels of intercultural contact, separation supports the maintenance of one's culture without connection between immigrant groups and mainstream society, while marginalization undervalues both cultural identity and contact with others (Paz Alencar, \& Deuze, 2017). Assimilation theories, in which the goal is that migrants adopt the culture and norms, and adapt to the institutions of mainstream society (Gordon, 1964), have been criticized for failing to acknowledge the cultural influence that immigrants have on their new society. If assimilation did not occur, and the result being the formation of a low-income 
immigrant underclass (Boyd, 2002), the fault was placed on the immigrant for being unable to adapt, under the assumption that this was a shared goal of everyone (Bloch, 2002). Glazer and Moynihan (1970) highlight the importance of the aspirations of migrants themselves in the settlement process. There is the possibility that migrants may not assimilate as a matter of choice (Bloch, 2002).

Increasing immigration on a global scale has increased ethnic and racial diversity in a growing number of societies, but has raised questions in the political sphere about integration of "ethnic" and "racial" groups into Western society (Reitz, Breton, Dion, Dion, Banerjee \& Phan, 2009). Canada has embraced support in integration as a policy, at least in rhetoric, and emphasizes the "two-way street" - the role of mainstream society in ensuring inclusion and cultural acceptance of newcomers (IRCC, 2017; OCASI, 2010; OCASI, 2012). The idea of integration in Canada has often been framed in opposition to the American "melting pot," or assimilationist model. In contrast to the rhetoric of immigrants giving up their culture for that of the host society, multiculturalism requires "mutual adjustment," that the native-born also adapt to the changes immigrants bring to their new country (McCoy, Kirova, \& Knight, 2016). McCoy et al. (2016) suggest that the real concern for integration is Canada's role, rather than that of immigrants. However, the generally lower economic standing of immigrants and racial minorities suggests that prejudice or structural inequalities still have a significant presence in the labour market and in access to societal resources. The narrative of concern over whether immigrants are able to adapt to Canadian society due to "cultural differences" has served as a means of "depoliticizing" race, while framing the cultural differences of immigrants as being to blame for preventing social cohesion with mainstream society (McCoy et al., 2016).

Despite Canada's reputation for being an inclusive and multicultural society, Canadian institutions, including those responsible for providing immigrant settlement support, more closely reflect Gordon's model on which the basis of organizational, program, and funding models are based on Western structure. Thus, many settlement programs are centered around the goal of teaching immigrants how to live and work in Canadian society. With a national narrative that problematizes immigrants and the prevalence of different cultures, programs and services catered to immigrants will be formed in response to these problems, rather than catering to the needs of immigrants. When policy is influenced by a Western narrative that currently does not view immigration and cultural diversity in a positive light, what is missed are the complexities of 
individual experience and situations, and the aspirations, skills, and strengths that immigrants bring to their new home. Aliweiwi and Laforest state that supporting diversity means going beyond economic support, and requires support for social integration, and fostering a sense of belonging; this is where many government-mandated programs fall short (Shields et al., 2016). This study argues that there is great value in ground-up approaches to services, which allows for responsive, innovative and relevant services to be provided to the people who need them. Solutions defined through policy, if policy is not in touch with the realities on the ground, will not be effective. Even with extensive research, organizations held to strict program guidelines cannot be equipped to respond in a timely manner to the needs of diverse local communities (Mukhtar et al., 2016). This view is in contrast to the principles of New Public Management, which has guided the settlement sector over the past two decades, and assumes efficiency of programming based on performance outcomes (Evans \& Shields, 2014). However, these measures are out of touch with ground-level realities, which is why the work of smaller community organizations and volunteers is invaluable. Front-line people working in local communities have a rich knowledge base which the formal sector and policy-makers can gain from (Jimeno, et al., 2010). 


\section{Chapter 4. Methodology \\ Research Design}

The question this study sought to answer was:

What do some grassroots and community organizations in the Greater Toronto Area see as the limitations and gaps in available public services for newcomers?

The two main objectives were, first, to discover what distinctive service offerings or specialized knowledge, can contribute to improving these services, both in the formal settlement sector and at the grassroots. Secondly, the study seeks to learn what challenges these grassroots and community organizations face in continuing and expanding their services, and how they can be better supported in their work.

A qualitative thematic analysis research approach was used for this study. The purpose of using a qualitative approach is to understand a particular phenomenon from the perspective of those experiencing it (Vaismoradi, Turunen, \& Bondas, 2013), in this case the perspective of those working in grassroots and community organizations in the GTA, who provide support services for newcomers. Vaismoradi et al. (2013) cite multiple research studies by Giorgi (1992), Holloway and Todres (2005), and Sandelowski (2010), noting that qualitative description "presents and treats research methods as living entities that resist simple classification, and can result in establishing meaning and solid findings" (Vaismoradi et al., 2013, p.399). Qualitative approaches are generally person-centered, and begin with an open-ended starting point (Holloway \& Todres, 2003 as cited in Vaismoradi et al., 2013). This method supports the goal of contributing the unique perspective of the participants to existing literature on the settlement sector. This desire to begin the research open-ended, and to allow opportunities for new insights to be gained from the participants is the logic for employing semi-structured interviews, so as not to be bound by a pre-determined list of questions, as with structured interviews or surveys.

Thematic analysis is used when the researcher wishes to employ a low level of interpretation to the data to allow a more nuanced account of the data (Vaismoradi et al., 2013). It takes a more descriptive approach to presenting the information gained from the interviews. Thematic analysis involves "analytically examining narrative materials from life stories by breaking text into small units of content and submitting them to descriptive treatment" (Sparker, 2005 as cited in Vaismoradi et al., 2013, p.400). Thematic analysis is used to identify, for 
example, the concerns of people about an event, or in this case a particular situation (Vaismoradi et al., 2013). Participants were asked why there was a need for the particular service they offered, what they identified as the greatest needs for newcomers based on their experience, and where they faced challenges in obtaining the resources they need to continue and grow their programs or services offerings.

There is a wide body of literature on the Canadian settlement sector, but less research has been done on the contributions of grassroots and community level organizations, particularly those that are not part of the formal settlement sector. Their work theoretically is less influenced by immigration and settlement policy, but instead by direct observation of the needs of their local communities. Similarly, a ground-up approach was used in researching these community organizations and initiatives, with the hope of expanding the findings beyond the biases of immigration literature and analyses from government and larger players in the sector. The goal is to contribute to knowledge-sharing in the sector through local, ground-up learning. There is the possibility that some of this learning might influence the work of larger players in the settlement sector, policy, or else garner stronger support for the work of community groups. The study will explore the work and impact of grassroots and community-based initiatives supporting newcomer communities in the Greater Toronto Area. Additionally, the study seeks to learn about the challenges they face and provide recommendations for relevant actors, including governments and settlement sector organizations on how and why to support these initiatives.

Finally, the study seeks to offer insights on practical solutions to newcomers' current settlement needs, by considering the distinctive knowledge of organizations who work in close personal contact with newcomer communities.

\section{Participants}

Participants from three organizations in the Greater Toronto Area were interviewed for this study: Newcomer Kitchen, Neighborhood Arts Network, and Culture Bridge Initiatives. Additionally, input was taken from two key informants who collaborate with similar organizations in their roles: a member of the Social Planning Council of York Region, and a staff member working for the municipality of Newmarket, under the umbrella of Recreation and Culture. Both these participants work closely with community organizations, and are looking at 
ways to support them and create connectivity in terms of social services for immigrants in their communities. These organizations or initiatives began because of people living and working in their communities who identified a need for newcomers and responded. A total of six participants from five organizations were involved in semi-structured interviews which discussed their work, their perception of the needs of newcomers, and the challenges their organization faced in providing these services.

Newcomer Kitchen is a program that has existed since 2015, and began to support Syrian refugees in Toronto when they were in hotels without a place to cook. It gave the women a space to cook, to have familiar food for themselves and their families at no cost, and expanded to become a source of income and a way to create social opportunities among the Syrian community. The program is also a way for them to share with their new communities, to have experience working and to gain the independence that comes with that (Newcomer Kitchen participant, June 19, 2018).

Neighborhood Arts Network, an initiative of the Toronto Arts Foundation, is a Torontowide network of over 1700 members, including artists, arts organizations, cultural workers and community agencies (Toronto Arts Foundation, 2018). It was launched in 2011 with the goal of connecting artists to the arts community and to resources. They also provide specific programs for newcomer artists through initiatives like the RBC Arts Access Fund, which supports newcomer artists who want to kick-start a project in Toronto but don't have the funds or resources to do so (Neighborhood Arts Network participant, July 12, 2018).

Culture Bridge Initiatives is working in York Region, which contains more suburban and urbanizing municipalities, where the context of immigration is very different than Toronto. Immigrant arrivals have been increasing in York Region, and Culture Bridge Initiatives saw the need to give people opportunities to socialize, to celebrate and to share their culture. They have been running cultural events and programs throughout the region since 2011. Initially, focus was primarily on the South Asian community in York Region, through programs such as cricket in schools and traditional Indian dance classes, but they have expanded to seek programming that caters to the various diverse cultures of the Region, primarily through their annual multicultural festival (Culture Bridge Initiatives participant, July 16, 2018).

A staff member working for the municipality of Newmarket in York Region, under the umbrella of Recreation and Culture, participated. She is responsible for the development and 
delivery of arts and culture programming, and also works with various community groups to support their infrastructure development and progress. She is seeking to see her role expand, particularly as Newmarket continues to become a more culturally diverse community through immigration. She believes that the municipality and various organizations outside of the settlement sector have a significant role to play in supporting immigrant settlement and integration (Newmarket Recreation and Culture participant, June 28, 2018).

The Social Planning Council of York Region has been around for about twelve years in York Region. They address economic and social challenges that marginalized populations face, including those with low income, newcomers, women, or homeless youth, and partner with other organizations in the region who serve the same causes. The member who participated also worked in collaboration with settlement organizations and other grassroots organizations serving immigrants (Social Planning Council of York Region participant, July 17, 2018).

\section{Data Collection and Analysis}

The participants were recruited through snowball sampling and cold-calling, with the inclusion criteria being broadly set to organizations providing services to immigrants which the researcher understood to be unique or innovative (i.e. in contrast to language classes or referral services). Purposive sampling of organizations was used, and diverse cases were sought out to provide the study with variation in an attempt to understand the broader picture (Symon \& Cassel, 2012). High level staff, managers, or founders of these organizations were asked to participate, as they have strong first-hand knowledge of the services and inner workings of the organization. For the purpose of confidentiality, however, they will henceforth be referred to by generic titles such as "staff" or "member." Permission was received from both the participants and their organizations to name these organizations in the study.

Through semi-structured interviews, the study sought to learn what similar themes, and what differences arise from asking more generally about these organizations; their contributions to immigrant settlement, their understanding of immigrant needs, and challenges they face in trying to support them. The interviews were transcribed and analyzed for prevalent and topics and sentiments within and throughout the five data sets. In thematic analysis, according to 
Vaismoradi et al. (2013), the researcher should consider both latent and manifest categories in the data, and cite the following steps by Braun and Clark (2006).

The analysis stage began with familiarization with the data through multiple readings of the interview transcripts, and initial codes were identified based on prevalence and depth of the topics discussed in each interview, and whether the topic was noted throughout in multiple interviews, and relevant data was collated to each code (Braun and Clark, cited in Vaismoradi et al., 2013). Initially, 26 categories were listed as the result of the open-coding process, including funding constraints and funder requirements, community infrastructure and investment, arts and culture, social participation, partnerships, innovation, economic and skills-building support, integration, direct or formal services, basic service needs, awareness of services, intra-sector competition, cultural awareness, municipal settlement structure, and newcomer contributions. The listed categories were considered in more depth due to their significance within the framework of learning more about newcomer needs from the perspective of the participants and considering the organizations' capacity. These categories were then collated into initial themes, drawing on initial ideas to form latent meanings within the data that were supported throughout multiple interviews. For example, it was noted that many of the categories referenced deeper institutional issues which reflected the challenges faced by settlement agencies. As instructed by Braun and Clark (2006), once themes were developed, they were checked to see whether they work in relation to the data collated into initial categories, and with the entire data set (Vaismoradi et al., 2013, p.402).

Three major themes were finally developed: responses to the needs of newcomer communities; the need for culturally and contextually relevant programming; and the need to build partnerships and to invest in people. Given the diverse sample, in analyzing participant responses, it was important to keep in mind the specific roles of participants and the organizational context in which they were working which could influence their viewpoints. When interpreting the data, the participant and organizational context must be kept in mind, and variations in responses were assumed to be partially influenced by the resources and the environment in which the participant works. When inducing meaning from the data, the following questions were kept in mind: Who are the participants and what influence does their professional role play in framing their understanding of the situation? What lens are they speaking from? In addition, the explicit and implicit reasons for the situations they described 
were incorporated into the analysis (Castleberry \& Nolen, 2018). The influence of federal immigration and settlement policy is important; this was not explicitly referenced in all the interviews, which could in part be because most of these organizations are at arm's length from the formal settlement sector.

The analysis of the data was influenced by critical discourse analysis, which offers a valuable lens from which to view immigration and settlement policy, and would suggest that the policy outcomes as a partial byproduct of societal discourse on migrants and migration. Critical discourse analysis emerged in the late 1980s in European discourse studies, led by Norman Fairclough, Ruth Wodak, Teun van Dijk, and others (Blommaert \& Bulcaen, 2000). The purpose of critical discourse analysis, as referenced by Wodak (1997) is to examine "structural relationships of dominance, discrimination, power and control as manifested in language" (Blommaert \& Bulcaen, 2000, p.448). It studies the relationship between language and the structures of society, and according to Chouliaraki \& Fairclough (1999), it is based on the notion that the processes that shape our economic, social and cultural landscape are influenced by the discourses created and distributed by those in power (Blommaert \& Bulcaen, 2000). Fairclough (1992) outlines three dimensions of discourse analysis: discourse as text; discourse as discursive practice, or as the distribution and circulation of text in society; and discourse as societal practice (Blommaert \& Bulcaen, 2000). The last dimension, discourse as societal practice, contains the "ideological effects of hegemonic processes in which discourse is a feature" (Blommaert \& Bulcaen, 2000, p.449). Foucault proposes that hegemony in every society is achieved through the control, selection, organization and redistribution of discourse (Foucault, 1971, p.8). Critical discourse analysis is based on the notion that these discourses inform societal practices, and subsequently our collective values and perceptions. It suggests that discourse forms power relations and ideology, and these relationships are seen by theorists in critical discourse analysis as problematic (Blommaert \& Bulcaen, 2000). The social dimensions of language are "the object of moral and political evaluation," and they are analyzed with the goal of influencing practical change in society, such as exposing abuse of power, giving voice to those without power, or mobilizing people against social injustice (Blommaert \& Bulcaen, 2000, p.449).

According to Blommaert \& Bulcaen (2000), critical discourse analysis seeks to offer prospects for change in society, through correcting discourses that enforce injustice and inequality. With this in mind, this study is influenced by discourse of migration and integration 
policy, and offers alternative discourses through gaining insights from those working most closely with migrants. This is significant because the dominant view of migrants in West, is arguably negative, or at the very best, tolerant; and the discourses that influence this ideological standpoint also have an impact on migration policy and settlement spending. Through the lens of critical discourse analysis, the view of migration as a 'problem' influences a political agenda of reform, in response to controversial notions of migrant membership, or belonging (Dubois-Shaik, 2014, p.715).

\section{Concepts}

This study conceptualized "settlement services" as "programs and supports designed to assist immigrants to begin the settlement process and to help them make the necessary adjustments for a life in their new country." "Integration" is the ability to contribute, free of barriers, to every dimension of Canadian life, including economic, social, cultural and political (Shields et al., 2016). The term "newcomers" is broadly used due to the analysis of the informal services sector. Depending on the level of government providing the service, new immigrants are defined as those who have been in Canada for 3-5 years and are not Canadian citizens. Refugees have specific terms and categories, with separate eligibility requirements, while those without status in Canada most often are not legally eligible for any formal settlement services. These concerns are less relevant in the informal sector, whose services do not often require a presentation of status nor restrict based on years since landing. Thus, the term "newcomer" will encompass all people who have recently arrived in Canada and who might benefit from formal and informal settlement services, regardless of legal status; whereas "immigrant" will differentiate from refugees, naturalized Canadian citizens, and those without status.

In the context of this study, settlement services or supports encompasses a diverse range of programs and services for newcomers to Canada, provided by a diverse range of organizations. They may be serving immigrants, refugees, or residents without status in Canada, or else seeking to support the agencies or communities that work to foster successful integration of these new Canadians. These include, but are not limited to, settlement and employment agencies, community centers, schools, faith-based organizations, umbrella organizations, municipal departments and community organizations. The Greater Toronto Area (GTA) has a 
vast and complex network of immigrant-serving organizations, the majority of which are heavily reliant on government funding to sustain their operations. In contrast, the formal settlement sector will specifically refer to organizations who are primarily funded by Immigration, Refugees and Citizenship Canada (IRCC) to provide direct settlement services to immigrants. These services are heavily focused on language supports, job assistance, and referrals to available community services, and will be referred to by IRCC's term of Service Provider Organizations (SPOs). 


\section{Chapter 5. Findings \\ Responses to the Needs of Newcomer Communities \\ Limitations to Institutional Programming}

A major contribution of community organizations and grassroots initiatives is their ability to fill gaps in service needs. The participants noted distinct needs which they identified through working with their clients, which may not be addressed by the formal programs currently provided by SPOs.

I think that's more of a limited practical resource that's offered there, and I think to really feel part of community you need to be celebrating who you are within that community. participant from Newmarket Recreation and Culture

The participants expressed the need, first, for services that are flexible enough to address the immediate needs of newcomers as they come up, and second to invest in long-term integration supports. The following examples provided by participants demonstrate this. Newcomer Kitchen is a strong example of the ability of grassroots initiatives to respond effectively to immediate needs. The program began in 2015 in response to a very specific need of the Syrian refugee community. The founder had heard stories of the refugee families arriving in Toronto, many of whom were stuck in hotels for weeks or months at a time. They had no access to kitchens and could not prepare food for themselves and Newcomer Kitchen began in response to this specific crisis, as a gesture of hospitality. The program is run out of The Depanneur, a venue that showcases culinary talent in Toronto, inviting amateur and professional guest cooks to host various food events. Through building off the knowledge and the resources they already possessed, and without support from funders, the Depanneur was able to extend the invitation to the newly arrived Syrian community, allowing them to use the kitchen to make some familiar food, share a meal and bring some leftovers home for their friends (Newcomer Kitchen participant, June 19, 2018).

So it was a response to a specific crisis and from that it became more generalized. And it expanded and developed mechanisms. And it adapted to their needs. So once they had 
kitchens the focus was now, "Well can I make more money? Can I participate socially or economically in the community?" And so we expanded to accommodate the changing situations. - participant from Newcomer Kitchen

Once these Syrian families were relocated in homes and had their own kitchens, the focus shifted. Newcomer Kitchen saw the valuable social dimension of this program, and the great support it was getting from the Syrian community. It was one of few - if any - programs in Toronto that was built on the value of what the Syrian refugees, and the women in particular, had to offer. It gave them a place to be social, a way to make food that reminds them of home, and a means of empowerment and income that is not provided by any formal service. According to Newcomer Kitchen, the project to date has 75 women participating and has put over $\$ 100,000$ into the pockets of the Syrian refugee families in just over 2 years (Newcomer Kitchen participant, June 19, 2018).

The money [the Syrian cooks receive] is incredibly validated and dignified ... also the opportunity for community building, for reconciliation, for peacemaking, for language skills, for job skills, confidence-building, and all of this happens very powerfully, in real time, in the kitchen led by women... all we have to do is hold the space for it to happen. We just facilitate entrepreneurship. We don't sit them in a classroom and tell them all the things they need to know about being an entrepreneur; we just got rid of the barriers so that they can do what they're already good at. - participant from Newcomer Kitchen

In working closely with the Syrian refugee community, Newcomer Kitchen noted the challenges they face with their classes at the settlement agencies, and the restrictions on financial support. They cannot earn past a certain amount of money, which seems counterintuitive if the goal is to encourage newcomers to be self-sufficient. Immigrants may find, because of such restrictions, that they are struggling against the very system that is set up to support them. Participants noted that the current structure of programming and classes is inflexible, which cannot accommodate the needs of individuals in diverse situations, nor does it acknowledge their strengths and try to build on them. The result is that opportunities for newcomers are limited, 
suggesting that either the structure or content of settlement classes must be reviewed.

Participants noted the lack of satisfaction among some newcomer communities with settlement classes and workshops. Some of the formal settlement programs were described by participants as providing marginal value, as Western-centric and inflexible, and the concern was that support should not be contingent on these programs, especially if immigrants and refugees are seeking other ways to become self-sufficient, through job hunting, or who must be at home to take care of children.

The response from everyone who hears about the project, and from the Syrian community, the participants, has been very positive, because as far as I can tell there isn't a single social program in the entire province that actually puts money in their pocket. And not just anyone. Specifically, government-sponsored refugees, and specifically the women, who have that many more intersectional barriers for participation... Almost every single person [that we serve] is on assistance of some kind or other. A lot of them have multiple family obligations whether they have multiple children or they have to do elder care or there's just social and cultural factors that suggest that they would not be out there getting a full time job... I mean they have to go to their English classes, they're not allowed to earn past a certain amount of money. All of these things constrain what opportunities are available, so we've tried to design our offering to thread that needle, to fit into exactly how much time they can do. participant from Newcomer Kitchen

A lot of times I think when people are coming from other parts of the world, they probably look at us and wonder, "What do you mean a program? What do you mean a class?" I mean we have to [have programs] but I think we also have to recognize that it's a very Western, modern day, funders way of doing programming. We have to be more flexible... They must think we're crazy with all our programs... - participant from the Social Planning Council of York Region

There is very limited opportunity to earn a source of income for newly-landed refugees, and specifically women, who face multiple intersectional barriers, including restrictions from 
taking full time work in order to be eligible for assistance. Newcomer Kitchen has been able to overcome some of these barriers through their program.

I think the reason [Newcomer Kitchen] is popular is that it is incredibly simple and obvious. Take a bunch of people who know how to do something really well, give them the opportunity to do what they're already good at, and make sure they get paid a dignified wage to do it... yet we can't find any funding to support this. [Money needs to be put] into a program that creates genuine, measurable, tangible opportunity for them. - participant from Newcomer Kitchen

As another example of this kind of programming, Neighborhood Arts Network began programming for newcomer artists as a result of a two-year study of artists in Toronto neighborhoods. They built connections with these artists, who then wanted something to happen. And Neighborhood Arts Network created a guide for newcomer artists in the city, of simple information such as where to get art supplies, find galleries and how to seek grants. They then got in contact with settlement organizations, knowing that there was limited capacity there in terms of providing information to artists. They currently run the RBC Newcomer Spotlight, which provides funding for newcomer artists who want to begin a project in Toronto but may not have the resources to do so. About 30 artists per year are awarded, and are then eligible for the mentorship component (Neighborhood Arts Network participant, July 12, 2018).

Another initiative of Toronto Arts Foundation and Neighborhood Arts Network is a grant program administered by Toronto Arts Council, where newcomer artists receive $\$ 5,000$ and are matched with a mentor (with an additional $\$ 5000$ going to their mentor). Through this initiative, the Toronto Newcomer and Refugee Artist Mentorship Program, the goal is for newcomer artists to work with an established artist in Toronto to get better integrated to the Toronto art scene. The program is designed to target the needs of each artist individually; so the structure of the mentorship is set by each of the artists and their mentor. Neighborhood Arts Network staff hold informal interviews to get to know the artists' goals, and about their artistic practice. This was the second year of the program, and in 2017, 19 artists received the grant. In earlier years of Neighborhood Arts Network's programming, staff noted they were working with newcomers who had been in Canada for about six years, and today meeting with some artists who have only 
been in Canada six months to a year due to recognition through of word-of-mouth and gained trust within the artist communities (Neighborhood Arts Network participant, July 12, 2018).

It's great to see how passionate the newcomer artists are in getting back to their art. So now we're starting to see some of the outcomes from last year's mentorship and it's really great to see them going back into their practice and happy again, doing what they love, and feeling more at home here in Toronto. - participant from Neighborhood Arts Network.

Through working closely with newcomers, in some cases for extended periods of time, the participants identified some prominent needs they found for their clients. After sets of interviews and consultations with newcomers, mentorship was identified as very important for clients of Neighborhood Arts Network. The level of mentorship with other artists, and through ongoing support and drop-in sessions with staff, was noted as very important to their clients. This aspect of the program helped newcomers feel better integrated. Newcomer artists also needed support with navigating the business side of practicing in Canada, but specific to the Arts, because of Art terminology and jargon that they may not be able to learn in general language classes. Neighborhood Arts network participants noted that, while there may be opportunities for other disciplines in terms of being supported towards career growth, there is less support for this in the Arts. Language and cultural barriers may also hinder newcomer artists, who may not necessarily know how to speak about their type of art in English, or may find that they have to do things differently in Canada to work in the sector.

For example, a female artist said she didn't feel comfortable to pitch her work to a curator because where she came from, that's not what you do, especially as a female. Because we're seeing people from all parts of the world, it's also understanding the culture that they're in and how they have to negotiate what they can or cannot do. participant from Neighborhood Arts Network

Neighborhood Arts Network also identified mental health as a concern. The organization serves newcomers of all immigration statuses, who have been in Canada for a range of time periods. They are concerned that clients may not have any mental or emotional support while 
waiting for a refugee claim, or dealing with other challenges of settling in a new country which may be unrelated to their professional work.

Of course we have support for art-making or finding a job but after that one year there is no other means of support around mental health, or even a person they can talk to if they're going through something...waiting for the refugee claim to come through, stuff like that that's not necessarily related to their art, as a profession. - participant from Neighborhood Arts Network

When asked whether newcomer artists have sought mental health supports, or asked Neighborhood Arts Network for this type of assistance, the study participants stated that the need for this support was noted mostly through interactions with their clients. Only through this kind of person-person interaction, as opposed to generalized programming, can such needs be realized.

At least from my perspective, that has not been identified [by the artists] as a need, it's just with our interactions with those artists... it would be nice to have more support for newcomer artists around mental wellness. But there's a lot of stigma in different cultures... so mental wellness through the Arts, and ways that those artists can feel more comfortable even just interfacing with it and then realizing, "Oh actually this is good for me" and then going deeper into it. - participant from Neighborhood Arts Network

Newcomer Kitchen and Neighborhood Arts Network have not only been able to provide direct sources of income to refugees and newcomers, but provide meaningful and dignified work, by building on the skills and talents of their clients. This is absent from many mainstream employment courses, which are generalized and far from guarantee income as a direct outcome of participation. The responsiveness and nimbleness of these organizations is demonstrated through how they evolved to serve the needs of their clients. This, in part, is due to their size, and fewer constraints due to where they get their funding. The caveat is that the inconsistency of funding for some of these smaller organizations, who may rely on donations and fee-for-service work, results in greater limitations in terms of their capacity to expand programming and to plan for the future. 
[The institutions and larger organizations] are all essential, but it's much harder for them to get things done in a way that is really gonna meet the needs of people that need something right now. Whereas a place like Culture Bridge, even Family Services - I find that there are some organizations that are even a little bigger than that, that actually can respond in a more timely, flexible way, to the needs of populations on the ground. And so those are the groups that I want to be working with." - participant from the Social Planning Council of York Region

\section{Excess Bureaucracy and Inflexible Program Funding}

Funding was noted as the greatest challenge in maintaining operations and delivering services. Concerns noted included to following: the absence of available funding, political considerations, bureaucracy of funding applications, competition for resources and the lack of core funding for non-profits. Most participants shared similar challenges in regards to funding, while noting the desire to expand their capacity and programs were the funding made available.

We don't do programs because we don't have core funding - we don't really even have program funding. We have a working board so every board member takes on the responsibility of different projects and initiatives. Doesn't mean we aren't looking for funding, but we don't have any so we continue to do this work. A lot of Social Planning Councils are actually losing their funding as municipal governments take on more of a lead role in social policy, economic policy, community development. I think they do a very different job than what we do, but that's kind of the current of what's happening right now. - participant from the Social Planning Council of York Region

You get funded for say three years and you're working with all these artists... and then let's say you lose your funding, or the funding changes, or your sponsor changes their priorities. So therefore you can't run that project the same way. But then there's that expectation from your participants, your clients, that you're there to support them in $X$, $Y$ and $Z$. So it's hard when things change, when it's outside of your control, or if it's 
because, you know, we have new people in government and they have different priorities. - participant from Neighborhood Arts Network

Long and complicated funding applications and eligibility requirements create additional barriers for these smaller organizations. Participants found that despite delivering programs which seem to align with government settlement service mandates, applications for funding are often denied for reasons relating to their organization's capacity. Further, they noted the challenges of changing funding criteria, or "shifting goal posts" due to political changes or funding cuts. Programs have had to stop running or change significantly due to missed funding milestones, sometimes due to the face that parameters to qualify have changed.

Newcomer Kitchen found that, despite many government and foundation funds which speak to what they are doing, including providing economic opportunity for vulnerable newcomers, encouraging community participation and supporting integration, the funding prerequisites prevent the initiative from qualifying. There are also prerequisites that do not make sense for all initiatives. For example, when Newcomer Kitchen began their work in response to a specific refugee community arriving in Toronto they did not qualify for funding due to their lack of charitable status and short time of operation, despite having gained an incredible amount of good publicity in local and national press and television, including a visit from Canada's prime minister (Newcomer Kitchen participant, June 19, 2018).

Six months in, we're like "Okay we're incorporated as a non-profit, let's get this funding." They say, "Oh well, no, you have to be doing this for one year." Well how could we have been doing this for one year, [the Syrian refugees] have only been here for six months? Right? So it was only people who were already doing it before they ever arrived that were eligible...The foundations required that you be charitable, and then when you look at what it actually takes to become charitable, not only is it an incredibly bureaucratically intensive process that involves audits and financials and legal, which you have to pay for somehow... [It's been] far more political and competitive and cutthroat than I thought. I thought the best interest of the refugees was in the defining criteria and it turns out that's not the case. - participant from Newcomer Kitchen 
So we have an offering that's unique and meaningful and creates opportunity for the community... [we need] to find more innovative ways to sustain the program, because, despite our best efforts over two years, we still haven't received any funding... When it's all said and done, only the very established players in the industry fall under the criteria, and so new players, you realize once you get to the table that you don't qualify. - participant from Newcomer Kitchen

These are challenges that are increased for smaller organizations, who may not have the administrative capacity or the sector knowledge to be successful in applying. These organizations were not funded by the IRCC, or specific immigration programs, but rather through individual donations, private sector or charitable foundations unrelated to immigration, including Ontario Trillium. The benefit to corporate donations or purchases noted by one participant was the elimination of bureaucracy associated with strenuous funding applications, and in some cases fewer restrictions in terms of how the money is used. However, the downside to private donations and corporate contributions is the precariousness, and sometimes the goals of private partners or other provincial funding streams may also change.

I think being a charity that's always something that can be quite challenging. Even though we have really strong partnerships, we never know what's going to happen... And [the artists] would like to see the program grow this way, because now their needs have changed because they've graduated. And sometimes you can't respond quickly or consistently to those needs... I want to do that but I just don't have the capacity to do that. - participant from Neighborhood Arts Network

Contributing to the challenges of capacity building is the lack of core funding, and shortterm funding contracts, which limit organizations' ability to invest in long-term planning and respond effectively to unplanned issues. Despite the fact that funders are not on the ground in the communities, decisions about what services are needed are made by funders rather than the community workers who see the situations first-hand. As a result, organizations often find their work is subject to the requirements of a specific funding stream rather than a direct response to 
the problems they see on the ground; or else they may work according to their own discretion, but sacrifice funding as a result. In response to the question of what may allow smaller organizations to have more flexibility, a participant suggested it largely depends on the funding sources.

Sometimes it's your funding sources, so if you have funders that have a little more flexibility. Or the leadership of the organization has a vision of what they want to achieve and it's bigger than just project-by-project. But a lot of times now funding isn't core funding...now it's more, "Please apply for this money based on this funding stream that we [the funders] have determined is the most important one." So you always have to gear everything you're doing towards that. - participant from the Social Planning Council of York Region

So what I find is with an organization like [local non-profit], the director says to us all the time, "You know the families. What do they need to come to me? We'll make that happen." So he's very generous and open with the money he has. He doesn't waste money, but when funding comes to you, and you have to report it down to the nickel and dime, it's like there's no trust there in terms of people knowing how and what to do... But when we have \$25,000 for a year to do things with, it's unbelievable how much small organizations who are able to be nimble and can respond to the community can achieve with that kind of money. - participant from the Social Planning Council of York Region

Culture Bridge's unique contribution to newcomer integration in Newmarket and the greater York Region area which they serve, is their view towards creating long-term social support that is culture-sensitive. The difficulty if funders determine the success of a project based on metrics, is that quantifying social supports or measuring outcomes such as increased cultural awareness or reduced isolation is extremely challenging, especially with limited resources to put towards research. York Region participants noted the actions that the municipalities and Local Immigration Partnerships are taking in response to a rapidly growing immigrant population in the region, but according to Culture Bridge Initiatives, funding that is specifically geared to the 
organization's goal of building social infrastructure has proven impossible. They found that almost all funding is geared to the delivery of direct services, but they see a critical need for investment in the future.

A challenge is finding additional resources from those who buy into the need for culture-specific social infrastructure development. People and funding. There is not a fund available that I am aware of that will listen to the social infrastructure story. Almost everything available has got to be delivery of direct service today. - participant from Culture Bridge Initiatives

My observation working with lots of folks and being part of an organization who looks at certain things: not to fund, but to invest in. there's a lot of short-term mindset in trying to achieve the deliverables of a particular funding so you're often times missing what's happening right there in the community. - participant from the Social Planning Council of York Region

\section{The Need for Culturally and Contextually Relevant Programming Responding to the Realities on the Ground}

In terms of existing programming, it is structured based upon a Western, individualistic mindset and the strict regulations around delivery and eligibility can mean that, when this structure becomes a challenge for those from different cultures or different circumstances, they are often not heard. The Social Planning Council of York Region has been present in communities of recent immigrants and refugees, working with organizations delivering programming to immigrants, and more recently seeking to support the Yazidi refugee families who arrived in Toronto over the past few years. The Social Planning Council of York Region was present during a summer program for some of the Yazidi children, which was implemented through a collaboration between various settlement organizations and institutions in that municipality. These organizations found through planning and early stages of the program's implementation that they needed to be flexible and able to respond to unplanned situations. Part

of the early learning was that the initial program guidelines did not all make sense once the staff 
were in front of the families (Social Planning Council of York Region participant, July 17, 2018).

I think a lot of the families are coming from parts of the world where survival has been the main thing, and families and communities are the ones that take care of each other... so the notion of programs that [are meant for different age groups] is kind of foreign to them. We have teenagers come in and say "My little cousin is with me today, can she come and stay with us, she's visiting?" Now most programs will say, "Well she's 11, you're 14, she has to go home..." But who are we serving? So we have to have that flexibility. The rules are part of it, but the exceptions are sometimes more than the rules. - participant from the Social Planning Council of York Region

Participants noted the importance of services and workers being in the communities where people live, or else ensuring that there is enough knowledge among community institutions to be able to provide the right information in the places where newcomers shop, work and take their kids to school. All participants from York Region voiced the concern that newcomers may not be aware of where to access services, may be prevented from accessing services due to language barriers and other obstacles, and that there is no cohesive system for finding these services. Organizations need to be more equipped to deal with a changing population with diverse needs, and this starts with communication between organizations, and with newcomer communities (Newmarket Recreation and Culture participant, June 28, 2018).

A lot of organizations think they understand the needs of people who are living in poverty, but I don't think that's true. In a situation where you've got a community of highly victimized people who have experienced violence and seen obscene things... We have no idea. We have a lot of learning to do and we need to figure out a way to do it. I think we're going to end up having to change some of the ways that we work with people based on what we learn. - participant from the Social Planning Council of York Region

Interviews from York Region also suggested that there is a lack of diversity within the relevant institutions, and there is a need for education and training of key decision-makers in 
terms of increasing cultural understanding. These participants emphasized the need for dialogue with newcomer communities in order to understand what the needs are, rather than prescribing solutions based on their own perspectives. Significantly, it was noted that there might be any number of reasons why a particular newcomer family may not have sought and found services.

Because if people don't come to you when you offer something, there's a lot of reasons why. But no learning happens because we actually aren't hearing why that's not working or why they're not coming...So there's a lot that we can learn from being in the community, and even now, being close to where people live, there's still things that prevent them from coming out and us giving them what we think they need - because we still aren't necessarily asking them everything that they need. - participant from the Social Planning Council of York Region

[In my role] the worst thing that I can do is assume what a community might like to see happen. So finding a way to truly embrace what the needs are but not just through my perspective. My perspective might be in support of what is truly relevant to that community rather than me suggesting what might work. I can be there in support. And I'd rather be able to have dialogues and what's difficult is, one, the language barrier and two, I may have a lack of knowledge of cultural customs in terms of reaching out to that community. participant from Newmarket Recreation and Culture

The value of having people on the ground was noted, in or near the communities where people live, to support them, to learn where they actually need support, and not just providing information on what services area available. With programs, they may not fall under what people need right now, or people may be ineligible. The recommendation was having people on the ground, and similar grassroots organizations who are able to be responsive, to act according to what the person in front of them needs in the moment.

Some groups noted to have been a very strong support to refugee communities in particular were faith organizations, other grassroots organizations, and independent volunteers of various immigrant communities. These groups are on the ground and are helping with the most basic, 
practical needs of people moving into a new community (Social Planning Council of York Region participant, July 17, 2018).

What we need is more people working in community, to be able to make the connections with volunteers and newcomer communities. What we know is working better than anything else is that there are groups that have emerged out of the communities - and they're actually usually not the communities that are in need. For example, the Yazidi community first came here three years ago so there wasn't a settlement area before they came. But the Jewish community, and the Arabic-speaking community in general, and a lot of other existing communities have really supported them. And some volunteer organizations - [who might] have some amount of donor-based funding, so they're not responsible necessarily to funders - but they're on the ground having those face-to-face conversations, helping people move into their homes, and doing very real, basic, practical things that people need when they move into a new community, especially when they can't speak the language. - participant from the Social Planning Council of York Region

So there's volunteers and I find faith organizations, like the mosques and some of the different faith groups, the people that they have within their own faith communities are doing a lot of the work, not just in this case but in a lot of cases. - participant from the Social Planning Council of York Region

One participant voiced some of the concerns in York Region, where there is a particular need for more community-level support, and who noted the need to acknowledge the influence that policy and social planning has had on the current realities for low-wage families in the region.

When you have issues that are happening on the ground and people are hurting, if you go back far enough, if you look at it deeply, there's always some type of social planning or economic decision that was made... whether it's building affordable housing or not, there's always a step somewhere back that resulted in this outcome. So homelessness, lack of affordable housing, precarious work being the biggest increasing reality in York Region, 
we have higher numbers of precarious, part-time, low-paid work than most other areas of the Greater Toronto Area. - participant from the Social Planning Council of York Region

\section{The Role Arts and Culture in Creating Community}

The participants from York Region identified one of the greatest concerns as the absence of culturally-relevant and social programming, and the lack of awareness of available services among newcomers. In Newmarket, it was noted that opportunities for people, particularly racialized people, to be social, to become part of their communities, and to celebration their music and culture.

A participant from Newmarket Recreation and Culture saw the opportunity to strengthen her role in terms of incorporating diverse cultural art and celebration, providing space for social integration, and providing more opportunities to socialize with the community. The hope is to eventually create a space where newcomers and racial minorities in the municipality have space to celebrate their own music and culture (Newmarket Recreation and Culture participant, June 28, 2018). The participant noted that a part of her role in creating this dialogue has been through supporting community and grassroots organizations like Culture Bridge Initiatives, through clearing obstacles to their success, and ensuring an understanding of cultural diversity embedded in the programming she runs and supports for the municipality.

I'd like to see some of the centers - like the library, this cultural center, the municipal offices - do a better job of making individuals welcome, and start dialogues about what we can do in terms of service provision. These could be enhancements to what might already exist within the settlement centers, where I think it's more of a limited, practical resource that's offered. But I think to really feel part of community you need to be celebrating who you are within that community. - participant from Newmarket Recreation and Culture

The role of arts and culture was cited by participants as playing a major role in community integration. Culture Bridge Initiatives' work is based in part on allowing people to keep connections to their homeland, while also placing emphasis on what people of diverse cultures 
have in common. The main focus of the organization has been on developing social infrastructure, events and spaces within the community that allow for meaningful and lasting connections between neighbors. More than that, their work seeks to provide an entry point for people to engage in intercultural dialogue, with the aim of challenging prejudices and fostering understanding (Culture Bridge Initiatives participant, July 16, 2018).

Culture Bridge Initiatives began primarily serving the South Asian communities in their municipality, they since expanded to others in the Region, while also becoming inclusive of the needs of other cultures. They work in schools and have run various workshops throughout York Region, including youth cricket and traditional Indian dance. Presently, their largest celebration is the Culture Bridge Festival, a celebration of world cultures which features art and music of the many different ethno-cultural groups in York Region (Culture Bridge Initiatives participant, July $16,2018)$.

Before our festival, there has never been anything close to what we have done up here. The difficulty has been in being able to articulate and to find the relevance between social infrastructure and doing work today. - participant from Culture Bridge Initiatives

Participants expressed that the value of giving newcomers space to share their culture is in providing confidence, forming community, and contributing to fighting prejudice and negative stereotypes among those who are not familiar with that culture. The initiatives in this study are unique to traditional settlement services in that their goal in integration is not to have newcomers acculturate to Canadian customs, but to allow them to contribute through bringing and sharing their own culture, through making and serving Syrian food, through sharing their art in a professional capacity, and through showcasing the music, dance and sport of their previous countries.

Not only is cultural understanding important at the individual level, limitations on cultural sensitivity at the institutional and political level can greatly influence policies. Participants stated that acceptance of diversity has to be done on real level, not just for show, but in terms of making real changes that acknowledge the needs of a diverse population. 


\section{Building Partnerships and Investing in People}

The strength of many of these groups is their ability to form strong inter-sector networks, but there is room for stronger supports and more meaningful partnerships. Strong partnerships are based on outcomes and mutual goals, but inter-sector collaboration acknowledges that different types of organizations have different things to offer with respect to these goals. A common theme was the resourcefulness of these organizations, which particularly shows in terms of their ability to attain funding and through creating connections with newcomer communities, and partnerships played a major role in this.

So we've created more of a reputation for ourselves, and there's also word-of-mouth and trust in the community...Not only is there trust with the artists but also with different settlement organizations. They have the ability to [tell newcomers to] contact Neighborhood Arts Network or the Toronto Arts Council, and then we're able to take them in and guide them... We work closely with [the city], and the Local Immigration Partnerships, and also with the employment and service centers. They then talk to their colleagues, so we're building a little bit of a support network of administrators who've been helping the rest of the way. - Neighborhood Arts Network

Because of limited funding in the non-profit sector, many similar organizations rely heavily on volunteers (Social Planning Council of York Region participant, July 17, 2018). As noted, the Social Planning Council of York Region works unfunded, by partnering with other organizations who may have staff and program funding. Similarly, the participant from Newmarket Recreation and Culture noted that she does a lot of work in supporting grassroots organizations, but currently does so in an unofficial capacity. The municipality is just at the beginning of reaching out to settlement organizations and immigrant communities, but there is a significant role that the department can play in both supporting newcomers and smaller culturebased organizations by giving them spaces to be social within the community (Newmarket Recreation and Culture participant, June 28, 2018). 
I would like in my role to better be recognized for the cultural side of my work. And I believe that means bridging with our settlement communities and I believe that's bridging with a lot of the organizations that can help with processes, whether that's finding seed money to start those projects, or where to find pathways to celebrate their community and culture. - participant from Newmarket Recreation and Culture

One of the major challenges identified among participants is the inability of some immigrants to access available services, whether due to lack of information, or because the structure of settlement services in the region is inaccessible. Participants suggested that information could be more easily provided to immigrants if organizations, institutions and community workers themselves were better equipped with the knowledge to answer their questions. The concept of central "hub" beyond the settlement centers was recommended by two of the participants. Culture Bridge, as a small non-profit working within their community, indicated that they saw an opportunity for them to play a significant role in this central point of contact for services information. What Culture Bridge found as one of the major struggles for immigrants and others seeking community services is that they get passed from one service worker to another, and have to tell their story again and again, in order to even find out if help is available.

What our role really should be doing a lot more of is to be a cultural hub where we can help the multicultural and linguistic community to find opportunities. We never thought that we are going to be the employment or mental health counselling agency...but what may be the outcome of your visit to our office is that you are not leaving with a list of phone numbers; you are there [with us] until we find the person who you should be speaking to. - participant from Culture Bridge Initiatives

These networks also play a role in newcomer awareness of services. Newcomers to the area may be hindered from accessing services by language barriers, lack of knowledge or money to navigate transportation, or inability to fulfill program requirements and eligibility. In these cases, it is important that various actors in the community have the information to let newcomers know what services are out there, and that lesser known organizations might be able to provide 
support that they cannot get from formal service centers. Newcomers access schools, work in the private sector, and have needs in recreation and health, and these institutions must be equipped with the knowledge to support them. Collaboration and communication with these groups working outside the settlement sector can support newcomers in becoming familiar with what is happening in their neighborhoods, and ensure that they are given the correct information.

We're talking about a time when people, even people who are just low-income and have perfect English, can have a hard time accessing services. People don't have that social capital and that's totally different than the language. That's knowing what to get, when to get it, and having a sense of advocacy for yourself... and so I think in those first months and years [in Canada] we have to be as absolutely accessible as possible. - participant from the Social Planning Council of York Region

Participants expressed the need for people on the ground, within residential communities, schools, community centers and libraries, to have access to the information that newcomers need. They noted that while programming is important, there are multiple barriers to people even accessing these programs which need to be addressed. The formation of partnerships between sectors, and meaningful collaborations with volunteers and community workers, was noted as an important was that organizations are able to get people out to these programs.

I actually have one of those very rare community partnership roles, which gives me the flexibility to do this type of work. Those types of roles don't exist a lot of places. They used to, especially in Toronto. I used to work in Toronto, we had neighborhood houses and community centers and community development workers, and it allowed for us to invest in the community. And those positions are not very well understood. So funders are saying, "Well, we don't have to have people on the ground, we have programs." But people need people. Not just the people who are providing a program, but the people who are there to get to know them, and respond to their needs in a way that is responsive. - participant from the Social Planning Council of York Region 
There's also I think a less collective responsibility or thinking that way, so we're trying to work with people to kind of inspire that engaged citizenry, that collective mindset as opposed to just fighting for yourself, and with growing inequality the reality is human beings are human beings - you have to take care of yourself. So the less there is to share around, people start to be thinking more about themselves... So we want to inspire more of a collective, community-building approach. - participant from the Social Planning Council of York Region

Neighborhood houses and community development workers which were more prevalent in the past, in Toronto, allowed for stronger relationships to be formed between people, and supported organizations who wanted to work together. In the absence of similar support, many organizations work in silos. Participants expressed the importance of relationships in beginning collaborative programming, but also raised concerns about the time required to establish these relationships. Some settlement agencies have begun this work in Toronto, through sharing of their staff expertise in support of volunteers. However, it was noted that the staff and the money to do this is not always available (Social Planning Council of York Region participant, July 17, 2018).

There is a great opportunity for more collaboration between institutions and grassroots organizations involved in immigrant support, and for support to be given to newer initiatives. Established settlement agencies have the opportunity to be looking into communities, seeing what initiatives exist and are thriving in the grassroots, and supporting them. However, this becomes a challenge given their own capacity limitations and competition within the sector. But if this can be overcome, participants expressed the value that this support could provide to smaller community organizations and volunteers, as a means of bringing innovation into the sector. Participants also expressed the potential role of municipalities and of settlement agencies to support smaller organizations through the development of organizational policy, support in gaining funding and building capacity, or offering training on working in the settlement sector and with vulnerable populations. In many cases, new models of social supports are having very real, fast and practical impact, but are limited for lacking the knowledge of the sector and of working with government requirements. 


\section{Chapter 6. Analysis and Discussion}

The participants working for grassroots organizations and initiatives for newcomers, stated that they were being driven to provide unique service offerings to newcomers because they saw gaps and limitations to available formal services. The primary limitations to institutional programming identified was the tendency for settlement agencies to be out of touch with the realities on the ground, and the inflexibility of larger agencies to respond to newcomer needs which do not fit within their program structures. The data suggests that there are innumerable issues specific to communities and to newcomer demographics which require people working on the ground, who are closer in touch with their needs, and who have the autonomy to respond to them. The participants' close connection to the people in the communities they serve influenced the work they did and the services they provided. The participants in this study directly or indirectly referred to their work as divergent to the "direct" or "formal" services provided by settlement agencies, which offer IRCC-funded programming. The services analyzed in this study ranged from employment and entrepreneurship support, to social and cultural programming. While the programs provided in settlement agencies through IRCC-funding addressed the more "practical" and short-term needs of immigrants, the participants noted that there was a need for programming which provided more holistic support in terms of newcomer integration.

Every participant placed primacy on understanding the unique cultural and contextual needs of the newcomers whom they served. They acknowledged that needs were different, not only for each ethno-cultural group, but for individuals within those groups, and that these needs do not end when a person attains a source of income and a place to live. They identified the tendency for government programming to lack culturally sensitivity, and thus the importance of asking who is really being served when program restrictions exclude the most vulnerable. The current program-based funding structure assumes that decision-makers in government or foundations know what the needs are in communities, and how best to address them. The findings from this study bring this assumption into question, and participants noted the tendency for formal programming to be very Western-centric and focused on economic goals, whereas social and cultural considerations tend to be a secondary concern. There is a heavy facilitating newcomer entry into the Canadian labour market, yet their individual skills, strengths, 
limitations, and experiences are often not considered when programs are designed, but instead a one-size-fits-all approach is taken.

Some of the participants expressed the sentiments of their clients towards the classes offered through IRCC, noting that they received more value from being given opportunities outside of the classroom, as well as the difficulties for some groups who faced barriers to attending classes amidst their other responsibilities. OCASI's 2012 study reflected these concerns and similar experiences among settlement staff with regards to employment training. Settlement workers who directed their clients to resume-writing or interview preparation workshops noted that their clients did not want to invest time in them (OCASI, 2012, p. 36). Programs for self-employment, in particular, were criticized by services workers, who noted that small businesses require personal networks, credit histories and knowledge of the Canadian legal and financial systems (OCASI, 2012, p.39). Participants in the OCASI study noted that the information offered through the workshops was generic despite complex and unique situations of their clients, and it was made more difficult due to client's lower English-language proficiency and unfamiliarity with business terminology (OCASI, 2012, p.39). Given the severe urgency for most immigrants on finding a means of income, their lack of enthusiasm for classes should not be interpreted as lack of motivation on the part of immigrants, rather it suggests a need to reevaluate the content of these programs. Just as funding streams determined by high-level decision-makers may be misguided in addressing the realities on the ground, there is the potential that employment lessons taught in a classroom setting may be out of touch with the realities of the low-wage, unprofessional job market where newcomers are often concentrated (Brodkin, 2011; Banerjee \& Lee, 2012; Jimeno et al., 2012). Given these concerns, there is great value in looking at some of the innovative, practical programming taking place in the grassroots, which has the ability to be more tailored and specific to certain newcomer groups.

Participants also suggested that some of the problems with inflexible program requirements are the result of higher-level structural issues. They noted that excess bureaucracy with applications, program restrictions and inadequate funding causes challenges with building capacity, and in some cases continuing initial program offering. As a second layer of difficulty, this structure creates competition between organizations, which becomes a challenge to effective partnerships and collaboration. The lack of core funding throughout the public service sector was noted as a particular concern. The participants expressed the need, first, for services that are 
flexible enough to address the immediate, most basic needs of newcomers as they come up, and second to invest in long-term integration supports. They understood integration to be a continuous process, and thus the importance of giving newcomers space to contribute, fostering belonging within their new communities, and combatting discrimination, which are often areas of programming where it is difficult to find financial support.

The broad scope of grassroots work was noted by the participants from the Social Planning Council of York Region and Newmarket Recreation and Culture, who work closely with many of these groups. They noted that a lot of volunteer work is being done by immigrant communities, faith organizations and grassroots initiatives. Many are doing great work, with emphasis on broader integration supports, removal of barriers to newcomers, and provision of basic and immediate needs. The participants emphasized the importance of government investment in this kind of ground-level work, in order to have more community workers available to support new immigrants and refugees, and ensure that they are aware of and able to access the services that are available to them. These organizations and initiatives need to have access to funding to be able to continue this work, and particularly access to core funding which allows them to respond in a timely and effective manner to the newcomers they serve. 


\section{Chapter 7. Conclusion}

While there is a strong body of literature which discusses the challenges faced by settlement agencies, there is less research on the work many grassroots organizations who do not operate as part of the formal settlement sector. Many non-profit organizations are responding to the growing immigrant populations in their communities and realizing that there is not enough support for them to successfully settle and integrate into their new cities. In response, many grassroots organizations and independent actors have taken on the responsibility of filling these services gaps through innovate and effective services that are in touch with the realities on the ground. A greater understanding of their work, and their insights on what supports are needed for newcomers, can contribute to knowledge-sharing in the sector, and possibly paint a picture of what stronger collaboration and partnership among diverse stakeholders, particularly more established SPOs, can look like.

Despite the necessity of these community-based initiatives in filling service gaps for newcomers, they receive no settlement funding, and very limited funding overall. The success of some participants in being able to partner with settlement agencies is an important lesson in the mutual value that can be gained from these connections. Here are organizations and initiatives who are providing meaningful and dignified work to newcomer communities, and in doing so allowing immigrants to put money and contribute value to the Canadian economy. Literature on multiservice agencies has noted the downfalls of "essentializing" immigrant groups (Sadiq, 2004), and defining clients as newcomers alone implies that they will be served as such, and as the participants noted, it is important that programs acknowledge the very different cultural and individual contexts. While newcomers need language training and orientation, there is heavy focus in formal services, even in job skills training, on orienting them to the "Canadian workplace" or the Canadian environment or services, and federal eligibility ends after immigrants qualify to apply for citizenship. On the other hand, the organizations in this study are offering services for artists, for cooks, for families, and acknowledge newcomers as community members, not as migrants to be prepared for the labour market. Grassroots approaches acknowledge the diverse needs, but also their individual strengths and contributions, which the flexibility of programming, and closeness to communities, allows them to build on. 
One major limitation of this study was the small sample size, with a participant pool of only six individuals. A larger sample would have allowed for more reliable results. It is also important to account for the very different contexts in from which each of the participants spoke of their experiences. For example, the variation in discussion of institutional problems, including discrimination or lack of cultural awareness among decision-makers, was an explicit concept in some interviews, but not all. Given the limited data, occurrences like these are difficult to accurately interpret. It is important to acknowledge that, while answers and depth of answers in sensitive areas may be due the real experiences of participants, there are also other factors to consider, including outsider status of the researcher, as well as participants' relative position of power within the context of this field to speak openly about these topics. Additionally, discrepancies in the participants' response about how much government funding is available to nonprofits can depend on the type of service they provide, the age and size of the organization, the participants' knowledge about grants, and other areas of concern.

While this MRP focused on learning about service offerings and challenges for workers at these organizations, opportunities for further research include studies on organizational functions of similar organizations, details on costs and funding, and the specific models used for successful partnerships. More insight into how stronger grassroots initiatives have been able to grow and maintain operations will be a valuable contribution to the settlement sector and to other grassroots organizations doing similar work.

This study has explored community organizations and informal supports, which provide important contributions to supporting newcomer integration in the Greater Toronto Area. Their impact is smaller in terms of numbers, but practical action is being taken at the ground level to respond to newcomer needs. These smaller organizations have the ability to be nimble, responsive, and to provide support that falls outside of official service mandates. They are closer to the newcomer communities that they serve, they see the needs first-hand, and invaluable lessons can be gained from the work that they are doing. 


\section{Bibliography}

Acheson, N., \& Laforest, R. (2013). "The expendables: Community organizations and governance dynamics in the Canadian settlement sector." Canadian Journal of Political Science, 46(3), 597-616. Retrieved from: https://search-proquestcom.ezproxy.lib.ryerson.ca/docview/1474178880/fulltextPDF/516069A58A464C70PQ/1 ?accountid=13631

Ashton, W., Pettigrew, R. N., \& Galatsanou, E. (2016). “Assessment of settlement services systems in Western and Northern Canada: Perceptions of settlement provider organizations." Canadian Ethnic Studies, 48(3), 69-89. Retrieved from: https://muse-jhuedu.ezproxy.lib.ryerson.ca/article/652608

Bacchi, C. (2000). "Policy as discourse: What does it mean? where does it get us?" Discourse: Studies in the Cultural Politics of Education, 21(1), 45-57. Retrieved from: https://journals-scholarsportalinfo.ezproxy.lib.ryerson.ca/details/01596306/v21i0001/45 padwdimwdigu.xml

Banerjee, R. (2009). "Income growth of new immigrants in Canada: Evidence from the survey of labour and in come dynamics." Industrial Relations, 64(3), 466-506. Retrieved from: https://search-proquest-com.ezproxy.lib.ryerson.ca/docview/224291812?pqorigsite $=$ summon

Banerjee, R. \& Lee, B. (2012). "Decreasing the Recent Immigrant Earnings Gap: The Impact of Canadian Credential Attainment." International Migration, 53(2), 205-218. Retrieved from: http://onlinelibrary.wiley.com.ezproxy.lib.ryerson.ca/doi/10.1111/j.1468$\underline{2435.2012 .00775 . x / a b s t r a c t}$

Banerjee, R. \& Phan, M. (2014) "Licensing requirements and occupational mobility amongst highly skilled new immigrants in Canada." Industrial Relations, 96(2), 290-315. Retrieved from: https://search-proquestcom.ezproxy.lib.ryerson.ca/docview/1535075703?pq-origsite $=$ summon

Bloch A. (2002). Theories of Migrant Settlement. In: The Migration and Settlement of Refugees in Britain. Palgrave Macmillan, London.

Blommaert, J., \& Bulcaen, C. (2000). “Critical discourse analysis.” Annual Review of 
Anthropology, 29(1), 447-466. Retrieved from: https://www-jstororg.ezproxy.lib.ryerson.ca/stable/223428?pq-origsite=summon

Boyd, M. (2002). "Educational attainments of immigrant offspring: Success or segmented assimilation?" The International Migration Review, 36(4), 1037-1060. Retrieved from: http://onlinelibrary.wiley.com.ezproxy.lib.ryerson.ca/store/10.1111/j.17477379.2002.tb00117.x/asset/j.17477379.2002.tb00117.x.pdf? $\mathrm{v}=1 \& \mathrm{t}=$ jayg80or\&s $=\mathrm{e} 568 \mathrm{~d} 7 \mathrm{~b} 31 \mathrm{~d} 134542 \mathrm{~d} 48225 \mathrm{a} 980148 \mathrm{c} 4 \mathrm{~d} 47$ $\underline{625082}$

Brodkin, E. (2011). "Policy work: Street-level organizations under new managerialism." Journal of Public Administration Research and Theory, 21(2), i253-i277. Retrieved from: https://www-jstor-org.ezproxy.lib.ryerson.ca/stable/25836109?pqorigsite $=$ summon $\&$ seq $=1 \#$ page scan tab contents

Burr, K. (2011). "Local Immigration Partnerships: Building welcoming and inclusive communities through multi-level governance." Horizons Policy Research Initiative, Citizenship and Immigration Canada, 1-9. Retrieved from: http://p2pcanada.ca/files/2011/10/Local-Immigration-Partnerships-Building-Welcomingand-Inclusive-Communities.pdf

Burstein, M. (2010). "Reconfiguring settlement and integration: A service provider strategy for innovation and results." Pathways to Prosperity: Canada, 1-58. Retrieved from: http://p2pcanada.ca/wp-content/uploads/2011/09/Reconfiguring-Settlement-andIntegration.pdf

Castleberry, A., \& Nolen, A. (2018). "Thematic analysis of qualitative research data: Is it as easy as it sounds?" Currents in Pharmacy Teaching and Learning, 10(6), 807-815. Retrieved from: https://www-sciencedirectcom.ezproxy.lib.ryerson.ca/science/article/pii/S1877129717300606

Citizenship and Immigration Canada. (2013). Local Immigration Partnerships handbook, pp. 117. Retrieved from : http://p2pcanada.ca/wp-content/blogs.dir/1/files/2013/08/LocalImmigration-Partnerships-Handbook-2013.pdf

City for All Women Initiative. (June 2015). Advancing equity and inclusion: A guide for Municipalities. Retrieved from: http://www.cawiivtf.org/sites/default/files/publications/advancing-equity-inclusion-web0.pdf 
Clarke, V., \& Braun, V. (2017). “Thematic analysis. The Journal of Positive Psychology,” 12(3), 297-298. Retrieved from: https://journals-scholarsportalinfo.ezproxy.lib.ryerson.ca/pdf/17439760/v12i0003/297 ta.xml

Couton, P., \& Institute for Research on Public Policy. (2014). Ethnocultural community organizations and immigrant integration in Canada. Ebook. Retrieved from: http://books1.scholarsportal.info/viewdoc.html?id=/ebooks/ebooks0/gibson_cppc/2014$\underline{10-25 / 1 / 10901334}$

Creswell, J., \& Poth, C. (2018). Qualitative inquiry and research design: Choosing among five approaches. Thousand Oaks, CA: Sage.

Darrow, J. H. (2015). “Getting refugees to work: A street-level perspective of refugee resettlement policy.” Refugee Survey Quarterly, 34(2), 78-106. Retrieved from: https://journals-scholarsportalinfo.ezproxy.lib.ryerson.ca/details/10204067/v34i0002/78 grtwasporrp.xml

Dubois-Shaik, F. (2014). “Analysing 'Migrant' membership frames through education policy discourse: An example of restrictive 'Integration' policy within Europe.” European Educational Research Journal, 13(6), 715-730. Retrieved from: http://journals.sagepub.com.ezproxy.lib.ryerson.ca/doi/abs/10.2304/eerj.2014.13.6.715

Evans, B., \& Shields, J. (2014). "Nonprofit engagement with provincial policy officials: The Case of NGO policy voice in Canadian immigrant settlement services." Policy and Society, 33(2), 117-127. Retrieved from: https://journals-scholarsportalinfo.ezproxy.lib.ryerson.ca/details/14494035/v33i0002/117 newppoviciss.xml

Foucault, M. (1971). “Orders of discourse.” Social Science Information, 10(2), 7-30. http://journals.sagepub.com.ezproxy.lib.ryerson.ca/doi/abs/10.1177/05390184710100020 $\underline{1}$

Government of Canada. (2012, June 10). Evaluation of the Multiculturalism Program. Retrieved from: https://www.canada.ca/en/immigration-refugeescitizenship/corporate/reports-statistics/evaluations/multiculturalism-program/section$\underline{1 . h t m l}$

Government of Canada. (2013 October 31). ARCHIVED - Notice - Supplementary 
Information to the 2014 immigration levels plan. Retrieved from:

https://www.canada.ca/en/immigration-refugees-citizenship/news/notices/supplementaryinformation-2014-immigration-levels-plan.html

Government of Canada. (2017a, November 1). Annual Report to Parliament on Immigration.

Retrieved from: https://www.canada.ca/en/immigration-refugees-

citizenship/corporate/publications-manuals/annual-report-parliament-immigration$\underline{\text { 2017.html }}$

Government of Canada. (2017b, November 1). Notice - Supplementary Information 2018-2020 Immigration Levels Plan. Retrieved from: https://www.canada.ca/en/immigrationrefugees-citizenship/news/notices/supplementary-immigration-levels-2018.html

Government of Canada. (2017c). Selection factors: federal skilled workers. Retrieved from: http://www.cic.gc.ca/english/immigrate/skilled/apply-factors.asp required?

Government of Canada. (2018, May 4). Funding. Retrieved from: https://www.canada.ca/en/immigration-refugees-citizenship/corporate/partners-serviceproviders/funding.html

Griffith, A. (2015, November 9). Multiculturalism transferred back to Canadian Heritage: Impact [Web log post]. Retrieved from: http://policyoptions.irpp.org/2015/11/09/multiculturalism-transferred-back-to-canadianheritage-impact/

Guest, G. \& McLellan, E. (2003). "Distinguishing the Trees from the Forest: Applying Cluster Analysis to Thematic Qualitative Data." Field Methods, 15(2), pp. 186-201 Retrieved from:

http://journals.sagepub.com.ezproxy.lib.ryerson.ca/doi/abs/10.1177/1525822X030150020 $\underline{05}$

Guo, S. (2014). Immigrants as active citizens: Exploring the volunteering experience of Chinese immigrants in Vancouver. Globalization, Societies and Education, 12(1), 51-70. Retrieved from: https://journals-scholarsportalinfo.ezproxy.lib.ryerson.ca/details/14767724/v12i0001/51 iaaceteociiv.xml\#body-s0002

Guo, S., \& Guo, Y. (2016). Immigration, integration and welcoming communities: 
Neighbourhood-based initiative to facilitate the integration of newcomers in Calgary.

Canadian Ethnic Studies, 48(3), 45-67. Retrieved from: https://muse-jhu-

edu.ezproxy.lib.ryerson.ca/article/652607/pdf

Hernandez-Plaza, S., Pozo, C., \& Alonso-Morillejo, E. (2004). The Role of Informal Social

Support in Needs Assessment: Proposal and Application of a Model to Assess

Immigrants' Needs in the South of Spain. Journal of Community \& Applied Social

Psychology, 14, 284-298. Retrieved from: https://onlinelibrary-wiley-

com.ezproxy.lib.ryerson.ca/doi/pdf/10.1002/casp.782

Immigration Refugees and Citizenship Canada. (2017). Evaluation of the Settlement Program, 1-

74. Retrieved from: https://www.canada.ca/en/immigration-refugees-

citizenship/corporate/reports-statistics/evaluations/settlement-program.html

International Institute for Sustainable Development. (2016). Comprehensive wealth in Canada:

Measuring what matters in the long run. International Institute for Sustainable

Development, 1-197. Retrieved from:

https://www.iisd.org/sites/default/files/publications/comprehensive-wealth-full-reportweb.pdf

Jimeno, C., Urquhart, D., Kilito., Canadian Electronic Library \& Social Planning Council of Ottawa. (2010). Best practices in supporting the integration of immigrant families through small ethno-cultural organizations, pp. 1-29. Ottawa, Ont.: Social Planning Council of Ottawa. Retrieved from:

http://books.scholarsportal.info/viewdoc.html?id=513833

Kim, S. (2016). "Silent counteractions of community organizations in a welfare partnership: a case study of South Korean workfare agencies.” Community Development Journal, 5(1), 95-113. Retrieved from: https://journals-scholarsportalinfo.ezproxy.lib.ryerson.ca/details/00103802/v51i0001/95 scocoisoskwa.xml

Ko, J. C. (2017). The ideal immigrant: Deconstructing immigrant success stories in Ontario Immigrant settlement agencies. Retrieved from: https://search-proquest-com.ezproxy.lib.ryerson.ca/docview/1951653385?pqorigsite $=$ summon

Lim, A., Lo, L., Siemiatycki, M., \& Doucet, M. (2005). "Newcomer Services in the Greater 
Toronto Area: an Exploration of the Range and Funding Sources of Settlement Services" (2005). Geography Publications and Research. Paper 41. Retrieved from: http://digitalcommons.ryerson.ca/geography/41

McCoy, J., Kirova, A., \& Knight, W. A. (2016). “Gauging social integration among Canadian Muslims: A sense of belonging in an age of anxiety." Canadian Ethnic Studies, 48(2), 21-52. Retrieved from: https://search-proquestcom.ezproxy.lib.ryerson.ca/docview/1815477022/fulltextPDF/F4C941CABBA2494EPQ/ 1? accountid $=13631$

Meinhard, A., Lo, L., \& Hyman, I. (2016). Cross-sector partnerships in the provision of services to new immigrants in Canada: Characteristics, relevance and constraints. Human Service Organizations: Management, Leadership \& Governance, 40(3), 281-296.

Retrieved from: https://journals-scholarsportalinfo.ezproxy.lib.ryerson.ca/details/23303131/v40i0003/281 cpitpoiccrac.xml

Mukhtar, M., Dean, J., Wilson, K., Ghassemi, E., \& Wilson, D. H. (2016). “"But many of these problems are about funds...': The challenges immigrant settlement agencies (ISAs) encounter in a suburban setting in Ontario, Canada.” Journal of International Migration and Integration, 17(2), 389-408. Retrieved from: https://link-springer-com.ezproxy.lib.ryerson.ca/article/10.1007\%2Fs12134-015-0421-5

Neudorf, E. G. (2016). "Key informant perspectives on the government of Canada's modernized approach to immigrant settlement." Canadian Ethnic Studies, 48(3), 91-107. Retrieved from: https://search-proquestcom.ezproxy.lib.ryerson.ca/docview/1880692342?pq-origsite=summon

OCASI. (2010). Framework for Modernized Settlement in practice: the OCASI vision, pp.1-9. Retrieved from: http://ocasi.org/downloads/OCASI ModernizedSettlement September2010.pdf

OCASI. (2012) "Making Ontario Home: A study of settlement and integration services for Immigrants and refugees." Ontario Council of Agencies Serving Immigrants, pp. 1-91. Retrieved from: http://www.ocasi.org/MOH

OCASI. (2018). About us. Retrieved from: http://www.ocasi.org/about-us Omidvar, R. \& Richmond, T. (2003).” Immigrant settlement and social inclusion in 
Canada." Laidlaw Foundation, pp. 1-5, Retrieved from: http://aidlawfdn.org/wpcontent/uploads/2014/08/wpsosi 2003 jan immigrant-settlement.pdf

Ontario Ministry of Citizenship and Immigration. (2015). Grants and Funding for Organizations. Retrieved from: http://www.citizenship.gov.on.ca/english/grantsandfunding/index.shtml

Ontario Trillium Foundation. (2018). What we fund: Action areas. Retrieved from: https://otf.ca/what-we-fund/action-areas

Osborne, S. P. (2006). “The new public governance?” Public Management Review, 8(3), 377. Retrieved from: https://journals-scholarsportalinfo.ezproxy.lib.ryerson.ca/details/14719037/v08i0003/377 tnpg.xml

Paz Alencar, A., \& Deuze, M. (2017). "News for assimilation or integration? examining the functions of news in shaping acculturation experiences of immigrants in the Netherlands and Spain.” European Journal of Communication, 32(2), 151-166. Retrieved from: http://journals.sagepub.com.ezproxy.lib.ryerson.ca/doi/full/10.1177/0267323117689993

Picot, G., Lu. Y. \& Statistics Canada. (2017, September 29). Chronic Low Income Among Immigrants in Canada and its Communities. Retrieved from: http://www.statcan.gc.ca/pub/11f0019m/11f0019m2017397-eng.htm

Reitz, J., Breton, R., Dion, K., Dion, K., Banerjee, R. \& Phan, M. (2009). Multiculturalism and social cohesion: Potentials and challenges of diversity. Springer

Richmond, T., \& Shields, J. (2005). "NGO-government relations and immigrant services: Contradictions and challenges." Journal of International Migration and Integration, 6(3), 513-526. Retrieved from: https://journals-scholarsportalinfo.ezproxy.lib.ryerson.ca/details/14883473/v6i3-4/513 nraiscac.xml

Rose, J., \& Preston, V. (2017). "Canadian municipalities and services for immigrants: A Toronto case study." Canadian Journal of Urban Research, 26(1), 29-39. Retrieved from: https://search-proquest-com.ezproxy.lib.ryerson.ca/docview/1918836810?pqorigsite $=$ summon

Sadiq, K. (2004). "The Two-Tier Settlement System: A Review of Current Newcomer Settlement Services in Canada." CERIS, 34, 1-42. Retrieved from: https://books1.scholarsportal.info/viewdoc.html?id=25337

Shan, H. (2009). "Shaping the re-training and re-education experiences of immigrant women: 
The credential and certificate regime in Canada." International Journal of Lifelong Education, 28(3), 353-369. Retrieved from: https://journals-scholarsportalinfo.ezproxy.lib.ryerson.ca/details/02601370/v28i0003/353 strarecacric.xml

Shields, Drolet \& Valenzuela. (2016). "Immigrant settlement and integration services and the role of nonprofit service providers: A cross-national perspective on trends, issues and evidence." Working Paper, Ryerson Centre for Immigration and Settlement, Ryerson University, pp.1-63. Retrieved from: https://www.ryerson.ca/content/dam/rcis/documents/RCIS\%20WP\%20201601\%20Shield s\%20et $\% 20 \mathrm{al} \% 20$ final.pdf

Shinnaoui, D. \& Narchal, R. (2010). "Brain Gain to Brain Waste: Individual Biases, Prejudice, and Discounting of Migrant Skills.” International Migration \& Integration, 11, 423-437. Retrieved from: https://journals-scholarsportalinfo.ezproxy.lib.ryerson.ca/details/14883473/v11i0004/423 bgtbwipadoms.xml Siemiatycki, M. \& Triadfilopoulos, P. (2010). “International Perspectives on Immigration Service Provision.” Mowat Applied Public Policy Research, pp. 1-25. Retrieved from: https://mowatcentre.ca/wpcontent/uploads/publications/5 international perspectives immigration.pdf

Somerville, K. \& Walsworth, S. (2009). "Vulnerabilities of highly skilled immigrants in Canada and the United States." American Review of Canadian Studies, 39(2), 146-161. Retrieved from: https://journals-scholarsportalinfo.ezproxy.lib.ryerson.ca/details/02722011/v39i0002/147 vohsiicatus.xml

Stasiulis, D., Hughes, C. and Z. Amery. (2011). Immigrant Settlement Policy in Canadian Municipalities. Montréal, QC: McGill-Queen's University Press.

Statistics Canada. (2016). "150 years of immigration in Canada.” Statcan.gc.ca. Retrieved from: https://www.statcan.gc.ca/pub/11-630-x/11-630-x2016006-eng.htm

Symon, G. \& Cassel, C. (2012). Qualitative Organizational Research: Core Methods and Current Challenges. SAGE Publications.

Toronto Arts Foundation. Neighborhood Arts Network. Retrieved from: https://torontoartsfoundation.org/initiatives/nan

Tossutti, L. S. (2012). "Municipal roles in immigrant settlement, integration and cultural 
diversity." Canadian Journal of Political Science, 45(3), 607-633. Retrieved from: https://www-jstor-

org.ezproxy.lib.ryerson.ca/stable/pdf/23321001.pdf?refreqid=excelsior\%3 $\%$ A $5 \mathrm{~d} 5 \mathrm{db} 3 \mathrm{~b} 3 \mathrm{db} 1$ $15378 \mathrm{a} 0 \mathrm{fca} 2 \mathrm{c} 538864 \mathrm{a} 4 \mathrm{c}$

Trudeau, D., \& Veronis, L. (2009). "Enacting state restructuring: NGOs as 'translation Mechanisms." Environment and Planning D: Society and Space, 27(6), 11171134. Retrieved from:

http://journals.sagepub.com.ezproxy.lib.ryerson.ca/doi/abs/10.1068/d0906

Truth and Reconciliation Commission of Canada. (2015). "What we have learned: Principles of truth and reconciliation." Truth and Reconciliation Commission of Canada, pp. 1-199. Retrieved from: http://www.trc.ca/websites/trcinstitution/index.php? $\mathrm{p}=890$

Türegün, A. (2013). "Immigrant settlement work in Canada: Limits and possibilities for professionalization." Review of Sociology, 50(4), 387-411. Retrieved from: https://journals-scholarsportalinfo.ezproxy.lib.ryerson.ca/details/17556171/v50i0004/387iswiclapfp.xml

Vaismoradi, M., Turunen, H., \& Bondas, T. (2013). "Content analysis and thematic analysis: Implications for conducting a qualitative descriptive study." Nursing \& Health Sciences, 15(3), 398-405. Retrieved from: https://onlinelibrary-wileycom.ezproxy.lib.ryerson.ca/doi/pdf/10.1111/nhs.12048

Vineberg, R. (2012). Responding to immigrants' settlement needs: The Canadian experience. Netherlands. Retrieved from: https://link-springercom.ezproxy.lib.ryerson.ca/book/10.1007\%2F978-94-007-2688-8

Xue, L. (2007). "A portrait of an integration process. Difficulties encountered and resources relied on for newcomers in their first 4 years in Canada: Evidence from three waves of the longitudinal survey of Immigrants to Canada." Citizenship and Immigration Canada, pp. 1-29. Retrieved from:

http://books2.scholarsportal.info.ezproxy.lib.ryerson.ca/viewdoc.html?id=396570\#tabvie $\underline{\mathrm{w}}=\mathrm{tab} 1$ 